\title{
INSUFICIÊNCIA RENAL AGUDA NA TERAPIA INTENSIVA
}

\author{
ACUTE RENAL FAILURE IN INTENSIVE CARE UNIT
}

José Abrão Cardeal da Costa ${ }^{1}$; Miguel Moysés Neto² \& Osvaldo Merege Vieira Neto²

\begin{abstract}
'Docente; 'Médico Assistente da Divisão de Nefrologia do Departamento de Clínica Médica da Faculdade de Medicina de Ribeirão Preto da Universidade de São Paulo.

CorRespondÊnciA: Dr. José Abrão Cardeal da Costa; Departamento de Clínica Médica da FMRP-USP - Divisão de Nefrologia; Av. Bandeirantes, 3.900 - CEP: 14048-900 - Ribeirão Preto - SP; E-mail: jacdcost@fmrp.usp.br.
\end{abstract}

COSTA JAC da, MOYSES NETO M \& VIEIRA NETO OM. Insuficiência renal aguda na terapia intensiva. Medicina, Ribeirão Preto, 31: 532-551, out./dez. 1998.

RESUMO: A insuficiência renal aguda (IRA) tem incidência em torno de 2 a $5 \%$, em pacientes hospitalizados, influenciada por fatores como: choque séptico, hipovolemia, uso de aminoglicosídeos, insuficiência cardíaca e radiocontrastes. Uma parte desses pacientes tem sido tratados em Unidades de Terapia Intensiva e, dependendo do quadro, altas taxas de mortalidade, podem ser atingidas. Nesse capítulo, apresentamos as causas mais comuns de IRA, enfatizando a sua prevenção no meio hospitalar. É importante, nesses casos, a distinção entre causas pré-renais e renais. Entre as causas renais, destacamos a necrose tubular aguda (NTA), geralmente provocada por hipoperfusão renal e/ou nefrotoxinas endógenas e exógenas. No tratamento, o balanço hídrico, aspectos nutricionais e diálise são fatores importantes a serem considerados. O tratamento dialítico, quando necessário, é realizado através de diálise peritoneal, hemodiálise intermitente, ultrafiltração, ou métodos contínuos de reposição da função renal.

UNITERMOS: Diálise. Insuficiência Renal Aguda. Necrose Tubular Aguda. Unidade de Terapia Intensiva.

A insuficiência renal aguda pode ser definida como perda da função renal, de maneira súbita, e potencialmente reversível independentemente da etiologia ou mecanismos, provocando acúmulo de substâncias nitrogenadas (uréia e creatinina), acompanhada ou não da diminuição da diurese.

\section{EPIDEMIOLOGIA}

A insuficiência renal aguda (IRA), geralmente, é considerada como uma doença do paciente hospitalizado. A incidência pode variar entre 2 a $5 \% \%^{(1,2,3)}$. Em um estudo prospectivo, com incidência de $5 \%{ }^{(2)}$, onde foram avaliadas duas mil, duzentas e dezesseis (2216) internações, 79\% dos episódios se correlacio- naram com hipovolemia, pós-cirurgia, administração de contrastes para RX e aminoglicosídeos. Os autores responsabilizaram fatores iatrogênicos como responsáveis em $55 \%$ dos casos. Em outro relato, foram analisados os fatores de risco para o aparecimento de IRA dentro do hospital ${ }^{(4)}$. Nesse trabalho, foram avaliadas uma mil e oitocentas e dezenove (1819) internações, com incidência de $2 \%$ de IRA a qual estava associada mais frequientemente com os seguintes fatores: choque séptico, hipovolemia, aminoglicosídeos, insuficiência cardíaca e uso de contrastes para RX. Além disso, outros fatores de risco são importantes no desenvolvimento da IRA como: idade avançada, doença hepática, nefropatia pré-existente e diabetes. 
As Unidades de Terapia Intensiva têm uma incidência elevada de IRA, podendo, em alguns casos, chegar a $23 \%{ }^{(5)}$, mas, em geral, têm incidência similar à do hospital como um todo ${ }^{(6)}$. A mortalidade é alta, especialmente nos casos em que há necessidade de diálise, com índices que variam de $37 \%$ a $88 \%{ }^{(6)}$. A despeito do avanço de novas técnicas de terapia intensiva e de métodos dialíticos contínuos, a mortalidade permanece alta ${ }^{(7)}$. As evidências, até o presente momento, mostram que a sobrevivência ou morte dos pacientes em Unidades de Terapia Intensiva dependem mais dos fatores relacionados ao paciente do que das formas de diálise empregadas ${ }^{(7)}$. Existem vários trabalhos, nas Unidades de Terapia Intensiva, tentando analisar os óbitos e correlacionálos com fatores preditivos através de sistemas como o APACHE II e III, definições de insuficiência de órgãos, síndrome de resposta inflamatória sistêmica, etc. Há, entretanto, dificuldades nessas análises, pela falta de trabalhos mais controlados e prospectivos $^{(7 / 11)}$.

\section{ETIOLOGIA}

\subsection{Pré-renal}

É a causa mais comum de azotemia aguda, em pacientes hospitalizados, com porcentagem que varia de $40 \%$ a $60 \%$ do total de acometimentos por IRA ${ }^{(12,13)}$. Não há defeito estrutural nos rins, simplesmente falta perfusão sangüínea adequada, no leito capilar renal, à medida que a pressão arterial média cai, progressivamente, abaixo de $80 \mathrm{mmHg}$. O seu diagnóstico é extremamente importante já que existe reversibilidade, nesses casos, em um (1) a dois (2) dias e, se persistir, pode levar os rins à lesão denominada de necrose tubular aguda (NTA) ${ }^{(14)}$. Durante a baixa perfusão renal, o volume urinário diminui e fica altamente concentrado com nitrogenados e quantidades mínimas de sódio, e é essa habilidade de retenção de sal e água que distingue, basicamente, a azotemia pré-renal das causas parenquimatosas de IRA ${ }^{(12,15)}$. Na Tabela I estão relacionadas as causas mais comuns de IRA pré-renal.

\subsection{Pós-Renal}

São menos freqüentes, em torno de 2 a $4 \%$ entre todas as causas de IRA e pode aumentar para $10 \%$ em faixas etárias mais avançadas ${ }^{(1,16)}$. Na Tabela II, podemos verificar as causas mais frequientes.
Tabela I - Insuficiência renal pré-renal (causas)

$\begin{array}{ll}\text { 1- Hipovolemia } & \begin{array}{l}\text { Hemorragias, perdas gastrintesti- } \\ \text { nais, terceiro espaço, queimadu- } \\ \text { ras, sobrecarga de diuréticos, fe- } \\ \text { bre. }\end{array} \\ \begin{array}{l}\text { arritmias, insuficiência cardíaca } \\ \text { débito cardíaco } \\ \text { congestiva, infarto agudo do mio- } \\ \text { cárdio, tamponamento pericárdico. } \\ \text { periférica }\end{array} & \begin{array}{l}\text { anti-hipertensivos. } \\ \text { choque anafilático, bacteremia e }\end{array} \\ \text { renal } & \begin{array}{l}\text { anestesia, cirurgias, síndrome he- } \\ \text { patorrenal }\end{array} \\ 5 \text { - Drogas } & \begin{array}{l}\text { agentes antiinflamatórios não hor- } \\ \text { monais, inibidores da enzima de } \\ \text { conversão da angiotensina, ciclos- } \\ \text { porina, agentes contrastados para } \\ \mathrm{RX} .\end{array}\end{array}$

Tabela II - Insuficiência renal pós-renal (causas)

1 - Obstrução bila- tumores da próstata e cérvix, fiteral dos ureteres

brose retroperitoneal idiopática, hemorragia retroperitoneal, ligadura acidental durante cirurgias pélvicas.

2 - Obstrução bila- cristais de ácido úrico e sulfa, teral dos ureteres edema, coágulos, cálculos.

(intraluminal)

3 - Obstrução em hipertrofia da próstata, carcinoma bexiga

de bexiga, infecção, neuropatia ou bloqueadores ganglionares.

4 - Obstrução uretral válvula congênita, estenose, tumor, funcional.

\subsection{Renal}

Nesse grupo, incluem-se todas as formas de lesões recentes ao parênquima renal (Tabela III). A necrose tubular aguda (NTA) é a forma mais freqüente de IRA em um hospital, responsável por $70 \%$ dos casos, seguida da incidência de 10 a $20 \%$ devido a nefrites intersticiais agudas e 1 a $10 \%$ o restante $e^{(12,13,17)}$. O termo NTA, embora não completamente apropriado, é utilizado universalmente pelos médicos, para designar quadro clínico de IRA, provocado por lesão isquêmica e/ou nefrotóxica, cuja reversão não mais será imediata após a remoção da causa inicial, ao contrário do que ocorre na IRA pré-renal e na maioria dos casos de IRA pós-renal ${ }^{(17)}$. 


\section{Tabela III - Insuficiência renal aguda: causas renais}

1 - Hemodinâmicas (isquêmicas):

2 - Nefrotóxicas

- Antibióticos

- Metais pesados

- Contrastes radiográficos

- Solventes orgânicos

- Venenos

- Químicos

- Anestésicos

- Agentes antiinflamatórios não hormonais

- Agentes nefrotóxicos endógenos

3 - Doenças glomerulares e vasculares

4 - Nefrite intersticial aguda politraumatismos, hemorragias, choque séptico, reações a transfusão, hemorragia pós-parto, pancreatite, gastroenterite.

aminoglicosídeos, tetraciclina, anfotericina, sulfa, aciclovir, foscarnet mercúrio, arsênico, chumbo, antimônio, ouro

etilenoglicol, tetracloreto de carbono, tolueno, gasolina, querosene pesticidas, herbicidas, veneno de cobra, de aranha e de abelha anilina, cresol

metoxiflurano, enflurano

mioglobina, hemoglobina, meta-hemoglobina, deposição tubular de cálcio, ácido úrico e oxalato.

glomerulonefrite difusa aguda, nefrite lúpica, panarterite nodosa, glomerulonefrites, hipertensão arterial maligna, síndrome hemolítica e urêmica, necrose cortical bilateral, trombose arterial renal bilateral, trombose da veia renal, trauma vascular, crise esclerodérmica.

antibióticos (penicilina G, meticilina, ampicilina, sulfa, cefalosporinas, rifampicina), drogas antiinflamatórias não hormonais, diuréticos (tiazídicos, furosemide), cimetidine, etc

\subsection{Necrose Tubular Aguda}

Pode ser induzida por hipoperfusão renal, nefrotoxinas endógenas e exógenas e, freqüentemente, por combinação de ambas.

A hipoperfusão renal: é a causa mais freqüente de lesão, levando à NTA, na vigência de trauma, cirurgia, hemorragia ou desidratação. Durante períodos de volume intravascular efetivo baixo os barorreceptores centrais são ativados. Em conseqüência, aumentos nos níveis de angiotensina II, norepinefrina e hormônio antidiurético provocam vasoconstricção e retenção de sal e água, numa tentativa de restabelecer o volume circulante efetivo; esses mecanismos agem para preservar a circulação em órgãos vitais, como coração e cérebro. A perfusão renal e filtração glomerular podem ser mantidas em níveis moderados de hipovolemia, devido principalmente à ação da angiotensina II através do aumento da resistência da arteríola eferente glomerular e estímulo das prostaglandinas vasodilatadoras intra-renais. Uma hipoperfusão mais grave, que não se compensa através desses mecanismos, pode resultar em azotemia pré-renal e, se a situação se agravar ainda mais, evolui para NTA. Algumas drogas, como os antiinflamatórios não hormonais e inibidores da enzima de conversão da angiotensina, podem interferir nessa auto-regulação e precipitar a hipoperfusão em pacientes com discreta hipovolemia ou insuficiência cardíaca. Portanto, essas drogas devem ser utilizadas com cuidado em pacientes com hipotensão ou insuficiência cardíaca congestiva ${ }^{(14,18)}$.

O baixo fluxo sangüíneo renal pode ocorrer na ausência de hipotensão sistêmica que chame a atenção, documentada em menos de 50\% das NTA pós cirurgias ${ }^{(2)}$. Quanto maior o tempo de isquemia, maior a repercussão clínica. Nos casos mais graves, com tempos maiores de hipoperfusão, pode haver necrose cortical. A necrose cortical pode ser vista, mais freqüentemente, em descolamento abrupto de placenta, aborto séptico, coagulação intravascular disseminada e choque grave ${ }^{(19)}$. 
As nefrotoxinas: devido à sua função de excreção e de concentração, o rim se expõe a várias substâncias endógenas e exógenas. Geralmente, a lesão nefrotóxica é reversível, previsível e passível de correção, se identificada precocemente. As lesões nefrotóxicas estão fortemente relacionadas não somente à sua concentração ou duração da exposição, mas a múltiplos fatores e à resistência do paciente em questão. Drogas nefrotóxicas, que são normalmente toleradas em indivíduos saudáveis, podem ser desastrosas em pacientes idosos e desidratados ${ }^{(17)}$.

A fisiopatologia da NTA é complexa, mas o entendimento dos fatores causais continua melhorando com o passar dos anos. Isso pode ser visto com mais detalhes em revisão mais recente ${ }^{(20)}$. A NTA isquêmica e nefrotóxica tem similaridades em sua fisiopatologia. A isquemia prolongada provoca hipóxia nos túbulos, as células necrosam e obstruem a luz tubular. Essas células lesadas promovem o que se chama de fluxo retrógrado, com o filtrado glomerular retornando à circulação, contribuindo, assim, para a diminuição da filtração glomerular. Um outro fator que contribui para a fisiopatologia da NTA é a vasoconstricção intra-renal que pode comprometer a circulação em até $50 \%$, o que dificulta a liberação de oxigênio, agravando a isquemia ${ }^{(14)}$. As alterações vasculares e tubulares explicam, em parte, as alterações na NTA. Durante a fase inicial de NTA isquêmica, a restauração do fluxo sangüíneo renal pode restabelecer a taxa de filtração glomerular (TFG), porém, a partir do primeiro e segundo dias, o aumento desse fluxo pode não elevar a TFG, cuja queda fica desproporcional ao aumento desse fluxo. Essa diminuição inicial do fluxo sangüíneo permanece com etiologia desconhecida, podendo estar envolvidos fatores como o sistema renina-angiotensina, sensibilidade anormal do sistema adrenérgico, tromboxano, etc. ${ }^{(19)}$. De qualquer forma, o que chama a atenção é que as células renais têm susceptibilidade maior à lesão, quando o rim está hipoperfundido. Várias observações clínicas e experimentais sugerem que a hipoperfusão e a nefrotoxicidade das drogas agem sinergicamente, aumentando a probabilidade de $\mathrm{NTA}^{(17)}$.

\subsection{Aminoglicosídeos}

Os antibióticos desse grupo, como a gentamicina, tobramicina e amicacina, são nefrotóxicos. $\mathrm{O}$ início de IRA pós administração dos aminoglicosídeos ocorre em 5 a $15 \%$ dos paciente tratados com essas drogas ${ }^{(3)}$. A IRA é tipicamente não oligúrica e, clinicamente, não é óbvia até cinco (5) a dez (10) dias após a administração. A sua toxicidade é dose-dependente e tem efeito cumulativo, logo as doses devem ser cuidadosamente administradas. Há agravamento e precipitação da lesão quando há fatores de risco envolvidos como: insuficiência renal preexistente, idade avançada, associação com anfotericina $\mathrm{B}$, furosemide, contrastes para RX, desidratação, isquemia renal, hipopotassemia e acidose metabólica ${ }^{(21,22,23)}$. Nesses casos, que freqüentemente ocorrem em pacientes internados em Unidades de Terapia Intensiva, deve-se evitar o seu uso. Quando necessário, monitorizar os parâmetros renais previamente e durante o tratamento com bastante freqüência. Quando houver sinais de nefrotoxicidade, deve-se suspender a droga ${ }^{(24)}$.

\subsection{Contrastes para $R X$}

A nefrotoxicidade desses agentes, como os diatriazoatos, iodotalamatos, iodoipuratos ocorre após a administração oral, arterial ou endovenosa ${ }^{(24)}$. Os maiores grupos de risco estão entre os pacientes com insuficiência renal preexistente (creatinina $>1,5 \mathrm{mg} \%$ ), e os diabéticos nefropatas. Os diabéticos com creatinina menor que $2,0 \mathrm{mg} \%$, quando recebem esse tipo de contraste, têm risco de desenvolver IRA em 3,6\%. Essa incidência vai aumentando, progressivamente, à medida que aumentam os níveis de creatinina, chegando até $80 \%$ para pacientes diabéticos com creatinina maior que $4,0 \mathrm{mg} \%{ }^{(25)}$. Outros fatores que podem aumentar esse risco são: idade acima de sessenta (60) anos, desidratação, insuficiência cardíaca e uma grande quantidade de contraste ${ }^{(25,26,27)}$. Os pacientes atingidos desenvolvem o quadro em vinte e quatro (24) a quarenta e oito (48) horas após a administração do agente. Essas alterações duram de dois (2) a cinco (5) dias, com retorno aos níveis basais, em dez (10) a catorze (14) dias para os casos mais leves e catorze (14) a vinte e um (21) dias para casos mais graves. Uma pequena porcentagem desses pacientes é submetida à diálise $^{(21,24)}$. A fisiopatologia é desconhecida, sendo fundamental a prevenção ${ }^{(27,28)}$. Como a prevalência é grande nos pacientes com insuficiência renal prévia (de 12 a 27\%) e nos casos de nefropatia diabética, preconiza-se nesses casos: hidratação adequada, minimização das doses de contraste, evitar o uso de drogas antiinflamatórias não hormonais e de exames contrastados repetidos ${ }^{(25,28)}$. O manitol e o furosemide não protegem dessa nefropatia ${ }^{(29)}$. A hidratação adequada, com líquidos endovenosos anteriormente à administração dos contrastes, tem sido a conduta de escolha para prevenir essa agressão ${ }^{(27)}$. Agentes de radiocontraste não iônicos, dímeros e monômeros, causam 
menos efeitos colaterais, porém estudos mostram que não há muitas diferenças entre todos esses tipos de contrastes com relação à incidência de IRA ${ }^{(25,27,28)}$.

\subsection{Drogas antiiflamatórias não hormonais}

Causas importantes de IRA, principalmente em pacientes com comprometimento renal prévio. Provocam lesão reversível da TFG, NTA e nefrite intersticial. Como já vimos anteriormente, tendem a alterar a TFG especialmente em pacientes com hipovolemia e doença renal preexistente, através da diminuição do metabolismo das prostaglandinas. Há uma concordância que essas drogas não podem ser prescritas com absoluta segurança aos pacientes com comprometimento renal, e quanto aos seus efeitos colaterais sobre os rins ${ }^{(29)}$.

\subsection{Hemoglobina}

A hemólise, associada com liberação de hemoglobina na circulação, e hemoglobinúria parece resultar em IRA somente quando há associação com outras anormalidades sistêmicas como a acidose, desidratação, choque ou outras condições relacionadas à diminuição da perfusão renal. Apesar de não haver provas suficientes, a administração de manitol, furosemide, alcalinização da urina e a manutenção da diurese parecem ser capazes de ajudar a evitar uma lesão ${ }^{(30,31)}$.

\subsection{Mioglobina}

As causas de mioglobinúria podem ser divididas em traumáticas (traumas, pós-exercícios, isquemia e pós-convulsões) e não traumáticas \{miopatias, coma prolongado, hiperpirexia, infecções, distúrbios metabólicos, sobrecarga de drogas e toxinas (narcóticos, sedativos, álcool, distúrbios eletrolíticos, veneno crotálico) $\}^{(31)}$. Um terço dos pacientes com mioglobinúria pode desenvolver IRA. O mecanismo da nefrotoxicidade é obscuro; entretanto parece estar associado à vasoconstricção renal, aliada à hipovolemia e acidose, provocando diminuição do aporte de oxigênio ao rim $^{(31)}$. A reperfusão pós-lesão muscular pode também ter um papel importante, através de uma grande liberação de radicais livres de oxigênio que poderiam lesar um rim já isquêmico ${ }^{(32)}$. Em algumas ocasiões, o tratamento precoce e vigoroso pode reverter a situação, como em descrições no atendimento de pacientes em grandes catástrofes. O tratamento já deve ser iniciado nos locais do acidente, com administração de bicarbonato de sódio, manitol e grande quantidade de líquiidos, mantendo um grande volume de diurese, em torno de oito (8) litros por dia, para pacientes de $75 \mathrm{Kg}$, até que a mioglobinúria desapareça (geralmente três (3) dias) ${ }^{(33)}$.

\section{DIAGNÓSTICO DIFERENCIAL}

A avaliação do paciente com IRA tem dois objetivos principais: determinar a etiologia e a extensão das complicações, o que pode ser feito através da história, exame físico e exames laboratoriais. Em alguns casos, pode ser difícil diferenciar a insuficiência renal pré-renal e NTA. Podem ser analisados com o intuito de fazer essa diferenciação.

\subsection{Volume urinário}

O termo anúria, significando falta de diurese, é utilizado pela maioria dos autores para diurese menor que $100 \mathrm{ml}$, nas vinte e quatro (24) horas. A oligúria descreve redução entre 100 a $400 \mathrm{ml} / 24 \mathrm{~h}$. A IRA não oligúrica é vista freqüentemente em pós-cirúrgicos, traumas, hipotensão, nefrotoxinas e rabdomiólise. Sua incidência gira em torno de 25 a $80 \%$ de todos os casos de IRA e pode passar despercebida, se somente for avaliada a diurese ${ }^{(34,35)}$.

\subsection{Densidade urinária}

A densidade de uma substância consiste no volume que determinada massa dessa substância ocupa. Pode ser obtida a partir da fórmula: densidade $=$ peso molecular/volume. Convencionou-se que a densidade da água a $37^{\circ} \mathrm{C}$ na pressão atmosférica ao nível do mar tem densidade de $1.000 \mathrm{mg} / 1 \mathrm{~L}$. Assim, soluções como a urina tem suas respectivas densidades avaliadas em relação à densidade da água. É influenciada pelo número de partículas de soluto por unidade de volume, mas principalmente pelo peso de cada partícula. A densidade urinária pode ter variação normal entre $1005 \mathrm{mg} / \mathrm{L}$ a $1030 \mathrm{mg} / \mathrm{L}$ mas considerando o estado de hidratação habitual de um ser humano encontra-se acima de $1015 \mathrm{mg} / \mathrm{L}$. Quando a densidade urinária se encontra na faixa de 1010-1015 próxima à do plasma (que é aproximadamente $1010 \mathrm{mg} / \mathrm{L}$ ) denominamos de isostenúria, o que seria compatível com NTA. Na IRA pré-renal, a densidade, geralmente, se encontra acima de 1020. Sofre alterações quando na urina se encontram dextranas, proteínas, carbenicilina, contraste radiológico, manitol e glicose. Essas substâncias podem passar mais facilmente para a urina quando há lesão renal, dando resultados alterados da densidade, que não correspondem à realidade da con- 
centração. A densidade urinária é um teste não específico e não fisiológico da reabsorção de água. Embora a densidade aumente proporcionalmente à osmolaridade urinária, em indivíduos normais, esse aumento fica prejudicado quando há lesão renal ${ }^{(12)}$. A análise da densidade perde, portanto, valor numa diferenciação entre IRA e NTA ${ }^{(12)}$.

\subsection{Uréia e creatinina plasmáticas}

Sob circunstâncias normais, a relação entre uréia e creatinina plasmáticas gira em torno de 10-15:1. Como a IRA pré-renal aumenta a difusão retrógrada da uréia filtrada e não da creatinina, a depuração de uréia cai rapidamente em relação à depuração da creatinina. Essa desproporção, que pode atingir níveis de até 60:1, é fortemente sugestiva de azotemia pré-renal ${ }^{(36)}$. Entretanto, na presença de NTA a queda das depurações de ambas as substâncias são semelhantes de tal maneira que as elevações dos seus níveis plasmáticos fazem retornar a relação para 10-15:1. É interessante ressaltar que o aumento desproporcional da uréia pode ocorrer na NTA quando há sangramento gastrintestinal, sepse e terapia com tetraciclina ${ }^{(12)}$, fazendo a relação voltar a ter valores elevados pela uréia.

\section{4. Índices urinários}

A partir de amostra de urina colhida aleatóriamente, mesmo que de pequeno volume $(10 \mathrm{ml}$ ou menos) e de uma amostra de sangue, pode-se obter parâmetros importantes para a diferenciação de IRA pré-renal e NTA. Essas são as duas situações clínicas mais freqüentes de IRA e que causam dificuldade diagóstica nas primeiras horas após sua instalação. $\mathrm{O}$ primeiro e um dos mais importantes desses parâmetros é a $\mathrm{FENa}^{+}$, que pode ser definida como o percentual de sódio excretado em relação àquele que foi filtrado. A FENa pode ser calculada a partir da seguinte fórmula:

$$
\mathrm{FENa}=\frac{\left[\mathrm{Na}^{+}\right] \mathrm{U} \times[\mathrm{Creat}] \mathrm{P} \times 100 \text {, onde }}{\left[\mathrm{Na}^{+}\right] \mathrm{P} \times[\text { Creat }] \mathrm{U}}
$$$$
\mathrm{U}=\text { urina e } \mathrm{P}=\text { plasma (Tabela IV). A }
$$

fração de excreção de sódio (FENa) é uma medida de quanto o rim está ativamente reabsorvendo sódio. Na IRA pré-renal, o rim está hipoperfundido; portanto reabsorve ativamente sódio e a FENa é freqüentemente baixa $(<1 \%)$, e a concentração de sódio na urina, geralmente, é menor que $20 \mathrm{mEq} / \mathrm{l}$. Ao contrário, quando há lesão do parênquima ou
IRA pós-renal, a FENa está usualmente $>3 \%$ e a concentração de sódio na urina acima de $40 \mathrm{mEq} / \mathrm{l}$. Infelizmente, há uma faixa de valores intermediários que, às vezes, não auxiliam no diagnóstico. A osmolaridade urinária não é influenciada pelo tamanho das partículas e sim pelo seu número, logo, a presença de proteinúria, glicosúria ou agentes de contraste radiológico não interfere com a sua medida. Na NTA, a osmolaridade urinária tende a ser igual à do plasma $(280 \mathrm{mOsm} / \mathrm{l})$ e fica em torno de 300 a 369 . Na faixa entre 350 a 500, há dificuldade de interpretação pois pode haver superposição dos resultados entre a IRA pré-renal e a NTA, e acima de $500 \mathrm{mOsm} / \mathrm{l}$ é grande a probabilidade de azotemia pré-renal. Há situações que podem atrapalhar a interpretação desses índices: utilização prévia de diuréticos, insuficiência renal prévia e alcalose metabólica ${ }^{(12,14,37)}$.

\section{5. Ácido úrico}

Mais recentemente, a excreção fracional de ácido úrico tem sido proposta como um teste mais específico e sensível em determinar a diferenciação entre azotemia pré-renal e $\mathrm{NTA}^{(38)}$.

\subsection{Outros métodos diagnósticos}

A ultrassonografia tem o propósito de diferenciação entre insuficiência renal crônica, uropatia obstrutiva, avaliação da perfusão dos vasos renais. Recursos como biópsia renal, arteriografia renal, pielografia ascendente são mais limitados e utilizados somente em casos específicos.

\section{7. "Testes diagnósticos"}

Utilizados de maneira prática na diferenciação

\begin{tabular}{|c|c|c|}
\hline Medidas & IRA pré-renal & NTA \\
\hline FENa (\%) & $<0,1$ a $1 \%$ & $>1 \%$ \\
\hline Na urinário $(\mathrm{mEq} / \mathrm{l})$ & $<20$ & $>40$ \\
\hline Osmolaridade urinária (mOsm/l) & $>500$ & $\sim 300$ \\
\hline Uréia /Creatinina Plasmáticas & $>40$ & $<15$ \\
\hline FE ácido úrico (\%) & $<7$ & $>15$ \\
\hline
\end{tabular}
entre NTA e IRA pré-renal. Comumente pode-se ex- 
pandir o volume sangüíneo, infundindo-se $1000 \mathrm{ml}$ de solução salina isotônica, num espaço de uma (1) a duas (2) horas, de acordo com a avaliação clínica da volemia, ou administrar $25 \mathrm{~g}$ de manitol ou $80 \mathrm{mg}$ de furosemide endovenoso. Nos casos do manitol e furosemide, pode-se repetir a dose a cada hora, no máximo duas (2) a três (3) vezes para o manitol e de uma certa forma mais vezes para o furosemide, que por não causar expansão do volume, é o mais utilizado. Em casos de IRA pré-renal, geralmente, consegue-se diurese acima de $60 \mathrm{ml}$ na primeira hora, o que não ocorre, na $\operatorname{NTA}^{(19,39)}$.

\section{PREVENÇÃO}

Um grande número de IRA provém de atitudes mais agressivas, retardo em medidas preventivas e desatenção por parte dos médicos, que através de melhor análise do paciente, evitando o uso de drogas nefrotóxicas, e agindo rapidamente ao menor sinal de complicação, podem evitar o desenvolvimento do quadro $^{(40)}$. Deve-se evitar a combinação de dois ou mais fatores potencialmente agressivos: agentes de radiocontraste, desidratação, icterícia, aminoglicosídeos, mioglobinúria e hemoglobinúria ${ }^{(17,21)}$.

Vários agentes farmacológicos têm sido propostos para prevenir NTA em pacientes de alto risco ou transformar casos oligúricos em não oligúricos. Por falta de estudos mais controlados, a sua utilização tem sido controversa. Os mais utilizados são: manitol, furosemide e dopamina. Outros agentes que estão em fase inicial de estudos são: bloqueadores de canal de cálcio, fator natriurético atrial e agentes alfa$\operatorname{adrenérgicos}^{(41)}$.

\subsection{Manitol}

Há discussões sobre se há vantagens ou não no uso de manitol na IRA humana, em comparação com a reposição de volume por outros métodos. Alguns autores acham que o manitol protege o rim em relação à cirurgia vascular, cirurgia biliar complicada e cirurgia cardíaca ${ }^{(42)}$. O manitol proporciona aumento da volemia, lembrando que ele se distribui quase que inteiramente no espaço extracelular e que pode provocar, pelo aumento da volemia, insuficiência cardíaca e edema agudo de pulmão nos casos de NTA. Outra manifestação de sua toxicidade é a NTA que pode produzir quando administrado em altas doses diárias (em torno de $200 \mathrm{~g}$ ) por período maior que três dias.

\subsection{Furosemide}

Os diuréticos têm sido utilizados de três maneiras para tentar alterar a história natural da NTA: profilaticamente, para prevenir IRA em situações clínicas, em que é complicação freqüente; na IRA precoce, na tentativa de evitar a sua progressão; e para acelerar a velocidade de recuperação, quando já houver lesão do parênquima ${ }^{(43)}$. Os efeitos do furosemide têm sido descritos como benéficos, inconsistentes ou prejudiciais, em vários trabalhos clínicos e experimentais. Alguns trabalhos iniciais sugeriam que altas doses $(2,0 \mathrm{~g})$ por dia poderiam ser benéficas, porém foram estudados pacientes com várias etiologias de IRA com evolução variada e comparações de maneira retrospectiva ${ }^{(44,45)}$. Em um trabalho prospectivo, utilizando grupo controle, verificou-se que a oligúria foi revertida ou prevenida em vinte e quatro (24) de vinte e oito (28) pacientes que utilizaram doses de 3,0 g por dia. Entretanto o número de diálises, duração de insuficiência renal e mortalidade não foram diferentes no grupo sem diurético ou com diurético ${ }^{(46)}$. Em outro trabalho, prospectivo, foram utilizadas doses de furosemide em torno de $3 \mathrm{mg} / \mathrm{kg}$ a cada seis (6) horas, durante vinte e um (21) dias ou até a recuperação. Não houve evidência de melhora na recuperação, porém alguns pacientes tinham aumento da diurese ${ }^{(47)}$. Em alguns casos, pode haver diurese sem que isso signifique melhora do quadro. Isso somente facilita o manuseio posterior. Em NTA já estabelecida, pelos dados existente até hoje, não se recomenda o uso de furosemide.

\subsection{Dopamina}

É uma catecolamina formada pela descarboxilação da L-DOPA. Dois tipos de receptores específicos têm sido descritos: receptores de dopamina 1 (D1), que estão localizados nas células musculares lisas, dos vasos, cuja ativação provoca vasodilatação através do mecanismo AMP cíclico, e receptores de dopamina 2 (D2), que são encontrados, predominantemente, em terminais pré-sinápticos de nervos do simpático pós-ganglionares. O estímulo de D2 provoca uma diminuição da liberação de noradrenalina e vasodilatação passiva. Ambos os tipos de receptores são encontrados no rim. A dopamina pode também ativar adrenorreceptores periféricos $\alpha$ e cardíacos $\beta$. Os seus efeitos são dependentes da dose: em baixas doses $(0,5$ a $1,0 \mathrm{~g} / \mathrm{kg} / \mathrm{min})$, a dopamina ativa primariamente receptores D1 e D2, provocando vasodilatação; em doses intermediárias ( 2 a $3 \mathrm{~g} / \mathrm{kg} / \mathrm{min}$ ) estimula 
receptores $\beta 1$, aumentando o débito cardíaco; em doses mais elevadas, estimula receptores $\alpha^{1}$ e $\alpha^{2}$, provocando vasoconstricção ${ }^{(41)}$. O efeito desejado para a dopamina é que mantenha a pressão arterial sistêmica, enquanto mantém ou aumenta o fluxo renal e a taxa de filtração glomerular, quando usada em doses baixas e intermediárias. A dopamina também provoca diurese e natriurese ${ }^{(41)}$. Em IRA já estabelecida, a dopamina é a substância vasoativa mais utilizada. Infelizmente, nunca foi estudada extensivamente, de maneira mais controlada ${ }^{(41)}$. Em alguns pacientes, resistentes à ação diurética, a adição de dopamina aumenta o fluxo urinário, mas, usualmente, sem a correspondente queda de nitrogenados. Em pacientes que respondem, a diurese ocorre quando a droga é administrada nas primeiras horas de oligúria. Quase não há resposta diurética, se for administrada após vinte e quatro (24) horas dessa baixa diurese ${ }^{(42,48,49)}$. A maioria dos estudos, em humanos, falha em mostrar convincentemente que a "dose renal" de dopamina previna ou melhore a função renal em IRA já estabelecida. Além disso, a dopamina, nessa "dose renal", pode apresentar efeitos colaterais importantes, como a precipitação de taquiarritmias, que podem acontecer mesmo em doses baixas que estimulam receptores $\beta^{1}$. Há dados que mostram que a dopamina pode ser utilizada em pacientes com déficit de função renal, que se submetem a exames com radiocontraste. Suas ações diuréticas e natriuréticas podem ser úteis, como simples suporte, em pacientes com IRA oligúrica, que estão hipervolêmicos e que não respondem a diuréti$\cos ^{(50 / 53)}$.

\section{QUADRO CLÍNICO}

A primeira alteração que ocorre em um paciente com IRA é a redução da TFG. Entretanto, a elevação dos níveis séricos de uréia e creatinina podem necessitar de algumas horas para serem detectados. Clinicamente a oligúria é um dos primeiros sinais clínicos a serem observados, mas pode não ocorrer. Nos casos de IRA não oligúrica pode haver retardo para a realização do diagnóstico, podendo acarretar maior lesão renal. Posteriormente, podem ocorrer manifestações decorrentes dessas duas situações tais como edema, hipervolemia, uremia, desequilíbrios hidroeletrolíticos e acidobásicos, etc.

O quadro clínico da IRA está relacionado, principalmente, à doença de base do paciente, e às alterações metabólicas decorrentes.

\subsection{Distúrbios acidobásicos}

O indivíduo com função renal normal apresenta uma taxa diária de produção de ácidos em torno de 0,8 a $1 \mathrm{mEq} / \mathrm{kg} / \mathrm{dia}$, em consequiência do metabolismo das fontes endógenas e exógenas de carboidratos, gorduras, ácidos nucléicos e proteínas. A principal fonte de íons $\mathrm{H}^{+}$ocorre com a oxidação de aminoácidos que contêm sulfa (metionina e cisteína). A homeostase acidobásica é mantida, normalmente, pelo tamponamento dos íons $\mathrm{H}^{+}$em nível intra e extracelular, com ventilação alveolar e com eliminação renal de $\mathrm{H}^{+}$, sendo esta variável, em condições normais, de acordo com a produção.

Os rins agem no sentido de reabsorver e ressintetizar $\mathrm{HCO}_{3}^{-}$perdido no tamponamento, bem como excretar parte da carga ácida, numa taxa de aproximadamente $55 \mathrm{mEq} / \mathrm{dia}, 30 \mathrm{mEq}$ na forma de $\mathrm{NH}_{4}$ e $25 \mathrm{mEq}$ na forma de ácidos tituláveis ${ }^{(54)}$, principalmente $\mathrm{H}_{2} \mathrm{PO}_{4}$. Assim, a taxa diária de excreção de ácidos pela urina $\left(\mathrm{NH}_{4}+\right.$ ácidos tituláveis $\left.-\mathrm{HCO}_{3}^{-}\right)$ correlaciona-se com a taxa de produção e, conseqüentemente, teremos, um balanço zero.

A taxa de produção de ácidos está relacionada ao catabolismo, com isso a queda de $\mathrm{HCO}_{3}{ }^{-}$varia de 1 a $2 \mathrm{mEq} /$ litro/dia nos pacientes não catabólicos, e 2 a $3 \mathrm{mEq} / \mathrm{litro} /$ dia nos pacientes hipercatabólicos (politraumatisados, pós-operatório, sepse, queimaduras, rabdomiólise, uso de corticosteróides) ${ }^{(55)}$. Nos pacientes com IRA e catabolismo normal, a acidose será lenta e gradual, com níveis séricos de bicarbonato em torno de 12 a $20 \mathrm{mEq} / \mathrm{litro}$.

Outras situações associadas à IRA poderão agravar a acidose (cetoacidose diabética, acidose láctica, drenagem biliar, perda de bicarbonato por diarréia, etc.).

A iatrogenia, principalmente reposição de $\mathrm{HCO}_{3}^{-}$, é a principal causa de alcalose metabólica nos pacientes com IRA.

\subsection{Eletrólitos e água}

A evolução do paciente vai determinar a reposição de eletrólitos, mas a quantidade de sódio, na ausência de edema, deve ser feita de acordo com as perdas urinárias ${ }^{(56)}$, e, geralmente, varia de 1 a $3 \mathrm{~g} / \mathrm{dia}$. A reposição de sódio deve ser feita de acordo com as quantidades preconizadas, e os alimentos devem ser preparados sem sal, sem utilização de temperos, molhos, embutidos e enlatados. 
Na IRA, os níveis séricos de magnésio e fósforo normalmente estão elevados, e os de cálcio, diminuídos, assim, a necessidade de correção vai depender desses valores. A elevação de fósforo raramente excede 7 a $8 \mathrm{mg} / \mathrm{dl}$, e a de magnésio a $5 \mathrm{mg} / \mathrm{dl}$. O agravamento da hiperfosfatemia e hipermagnesemia se dá pelo uso de antiácidos, contendo hidróxido de magnésio, e laxantes à base de fosfato. O risco da hiperfosfatemia é a deposição de cálcio nos tecidos moles, em conseqüência do aumento do produto $\mathrm{Ca} \times \mathrm{P}(>70)$. O nível sérico de cálcio varia entre 5 e $8 \mathrm{mg} / \mathrm{dl}$, não havendo diferenças na fração ionizada/total ${ }^{(57)}$.

Os rins são responsáveis por excreção de $90 \%$ da carga ingerida de potássio, sendo o restante eliminado nas fezes. Nos pacientes com IRA, evoluindo com catabolismo normal, o aumento de potássio é de até $0,5 \mathrm{mEq} / \mathrm{litro} / \mathrm{dia}$, mas, em situações de hipercatabolismo, esse aumento pode ser de 1 a $2 \mathrm{mEq} /$ litro/dia, acompanhado de aumento nos níveis de creatinina, uréia, fósforo, ácido úrico, e queda no $\mathrm{HCO}_{3}{ }^{-}$séri$\mathrm{co}^{(58)}$. O grau de toxicidade do potássio, na IRA, estará mais relacionado ao seu nível sérico ${ }^{(59)}$, o qual, geralmente, está acima de 7 a $9 \mathrm{mEq} / \mathrm{litro}$. Os sintomas são de fraqueza, paralisia muscular e alterações na condução cardíaca, podendo levar a assistolia. A hipocalemia pode ocorrer em algumas situações como: nefropatias por aminoglicosídeos, anfotericina B, hepatopatas crônicos, etc.; e, em alguns casos, na fase de recuperação da IRA, com poliúria persistente.

Os pacientes com IRA têm taxa de produção de água endógena em torno de $300 \mathrm{a} 400 \mathrm{ml} / \mathrm{dia}$, a qual variará de acordo com a taxa de catabolismo, aumentando nos estados de hipercatabolismo, nos pacientes com aumento da massa muscular e quando houver diminuição da gordura corporal. As perdas insensíveis estão em torno de $12 \mathrm{ml} / \mathrm{kg} / \mathrm{dia}$, podendo aumentar nos estados de febre, perdas gastrintestinais, etc. A reposição de água é baseada na diurese, portanto, é importante saber se o paciente se encontra em anúria ou oligúria. Para cálculo da reposição, usamos a seguinte fórmula: administração de líquiidos = volume urinário de $24 \mathrm{~h}+$ perdas insensíveis + outras perdas, se houver - água endógena.

\subsection{Creatinina}

A relação normal entre nitrogênio uréico sangüíneo e creatinina plasmática varia de 10 a 15:1, e, quando esse valor é superior a 20:1, se torna sugestivo de IRA pré-renal, pois, nessa condição, ocorre transporte aumentado de sódio no túbulo proximal, o que determina maior reabsorção passiva de uréia. Os ní- veis de creatinina tendem a aumentar, progressivamente, em torno de 0,3 a $0,5 \mathrm{mg} / \mathrm{dl}$ por dia, na necrose tubular aguda, e em nível mais lento na IRA pré-renal. Na IRA hipercatabólica, esse aumento pode ser igual ou superior a $1 \mathrm{mg} / \mathrm{dl}$ por dia.

\section{TRATAMENTO DA INSUFICIÊNCIA RENAL AGUDA}

\subsection{Nutricional}

A atenção a fatores nutricionais e metabólicos pode prevenir muitas das complicações da insuficiência renal aguda (IRA). A ênfase no manejo dos pacientes com tal insuficiência está diretamente relacionada a prevenir complicações, pois a função renal, usualmente, começa a melhorar espontaneamente, após duas a quatro semanas. O suporte nutricional é muito importante nos pacientes com IRA, uma vez que estes pacientes apresentam alto risco para desenvolver desnutrição, em conseqüência do hipercatabolismo e à reduzida ingestão de nutrientes ${ }^{(60)}$. A desnutrição proteicocalórica inclui, além da demora na cicatrização, alteração na função imune, aumento do risco de infecção hospitalar, redução de massa e atividade muscular $^{(61,62)}$. O regime terapêutico para a IRA varia consideravelmente, especialmente quando a doença ou injúria causadora da IRA também causa um aumento do catabolismo das proteínas corporais. Em qualquer esquema de tratamento, o volume e composição de todo fluido, calorias, geração e perdas nitrogenadas devem ser quantificados, assim como o grau de insuficiência renal, depósito de proteína corporal, e o impacto metabólico de outras doenças. A ingesta de líquiidos, eletrólitos, e sais minerais deve ser estritamente controlada para evitar sobrecarga hídrica e anormalidades dos eletrólitos plasmáticos, cálcio, fósforo, etc. Assim limitará o acúmulo de derivados nitrogenados e acúmulo de fosfatos, sulfatos, e outros íons inorgânicos, que resultam da digestão e metabolismo das proteínas da dieta ${ }^{(63)}$. O tratamento dietético consiste em prover substratos suficientes para o paciente com vários graus de estresse. Embora esse suporte seja similar àqueles estabelecidos para tratamento de pacientes com insuficiência renal crônica (IRC), eles são mais difíceis de alcançar porque a perda aguda da função renal não permite que ocorram processos adaptativos. Pacientes com IRA são menos hábeis para regular o balanço hídrico, o sódio, o potássio e outras substâncias, do que aqueles com IRC. Tais alterações, como sobrecarga hídrica, hiponatremia, hipercalemia, 
hiperfosfatemia, parecem ocorrer mais comumente em pacientes com IRA. A orientação dietética deve controlar algumas consequiências da uremia, melhorar o estado nutricional do paciente e, conseqüentemente, contribuir para diminuir a taxa de morbidade e mortalidade dos pacientes com IRA.

\section{CONSEQÜÊNCIAS METABÓLICAS}

\subsection{Metabolismo energético}

O consumo de oxigênio está aumentado em aproximadamente $20 \%$ do basal ${ }^{(64)}$.

O metabolismo energético, prejudicado na IRA, parece ser determinado pelas complicações adicionais. Na falência de múltiplos órgãos, o gasto energético é menor em pacientes com IRA associada do que naqueles sem distúrbios renais ${ }^{(65)}$.

Pacientes com IRA, quando bem dialisados, não apresentam aumento do gasto energético e, sim, tendência à diminuição do consumo de oxigênio, considerando apenas a IRA.

\subsection{Metabolismo das proteínas}

Na IRA, freqüentemente, ocorre balanço nitrogenado negativo, devido ao aumento na degradação de proteínas e diminuição na utilização de aminoácidos na síntese protéica pelo músculo esquelético ${ }^{(66)}$. Isso se deve ao aumento da captação de aminoácidos pelo fígado e incremento da neoglicogênese e síntese de proteínas de fase aguda ${ }^{(67)}$. Níveis aumentados de catecolaminas, glucagon e cortisol podem ser importantes no catabolismo protéico, na IRA ${ }^{(68)}$. A acidose tem sido identificada como importante fator contribuinte do catabolismo protéico. Pacientes com IRA que receberam mais de $1 \mathrm{~g}$ de proteína por quilograma de peso corporal apresentavam um déficit nitrogenado menor do que pacientes que recebiam menos de $1 \mathrm{~g} / \mathrm{kg}$ de peso corporal por dia. Esse fato estaria relacionado ao aumento na síntese protéica ${ }^{(69)}$.

\subsection{Metabolismo dos carboidratos}

A IRA está comumente associada à hiperglicemia, seja pela acidose ou pelo próprio estado catabólico, ou devido a uma resistência à ação da insulina e um defeito no pós-receptor, causando um metabolismo deficiente de glicose $^{(70)}$.

As alterações metabólicas da glicose e das proteínas estão inter-relacionadas na IRA. O desequilíbrio entre a disponibilidade de glicose e sua utilização pelas células parece acelerar o catabolismo protéico ${ }^{(70)}$.

\subsection{Metabolismo lipídico}

O metabolismo lipídico está alterado na IRA. Ocorre um acúmulo de lipoproteínas ricas em triglicérides (VLDL e LDL) e de colesterol, mas a HDL parece estar diminuída ${ }^{(71)}$. A atividade da lipase lipoprotéica e hepática está diminuída em até $50 \%{ }^{(68)}$.

\subsection{Eletrólitos}

Na IRA, geralmente, ocorre hipercalemia, hiperfosfatemia e hipocalcemia. Esta diminuição do cálcio é devido a uma elevação no fósforo sérico e resistência ao efeito do $\mathrm{PTH}^{(72)}$. Os níveis de 1,25 $(\mathrm{OH})_{2} \mathrm{D}_{3}$ são variáveis em função da produção e do "clearance" estarem reduzidos ${ }^{(73)}$.

\subsection{Desnutrição na IRA}

A desnutrição, na IRA, ocorre, geralmente, devido ao aumento das necessidades nutricionais e a um aporte reduzido . Entre as causas, podemos verificar um acúmulo das toxinas do metabolismo urêmico e alterações na concentração plasmática de hormônios catabólicos (Tabela V). O paratormônio se encontra elevado, e o mesmo é reconhecidamente hipercatabólico ${ }^{(72)}$. Também foi observado, em alguns pacientes, um aumento na atividade proteolítica sérica, sugerindo tanto uma elevação na quantidade de proteases quanto uma redução nos seus inibidores ${ }^{(68)}$.

\begin{tabular}{|l|}
\hline $\begin{array}{l}\text { Tabela V - Causas de desnutrição na IRA (adapta- } \\
\text { do de Wolfson \& Koplle }\end{array}{ }^{(60)}$ ) \\
\hline HIPERCATABOLISMO \\
- Hormônios \\
• Cortisol \\
• Glucagon \\
• PTH \\
• Resistência à ação da insulina \\
- Proteases \\
- Doenças associadas ou procedimentos cirúrgicos \\
DIÁLISE \\
- Perdas protéicas (diálise peritoneal) \\
- Perdas de aminoácidos (hemodiálise e diálise perito- \\
neal) \\
- Catabolismo associado à incompatibilidade de mem- \\
branas \\
INADEQUADA INGESTÃO ALIMENTAR \\
DESNUTRIÇÃO PRÉVIA
\end{tabular}


Outras causas que contribuem para a desnutrição, associadas ao efeito catabólico da uremia per se, são: a) anorexia e vômitos; b) presença de infecção, hipotensão, traumatismo cirúrgico e rabdomiólise; c) perda de nutrientes por meio de fístulas; d) perdas de aminoácidos, glicose e vitaminas solúveis na água durante a diálise ${ }^{(74)}$; e e) a própria diálise é um fator hipercatabólico devido à biocompatibilidade das membranas do capilar (reações do paciente como resultado do contato do sangue com as membranas do capilar).

A perda de glicose pelos pacientes em hemodiálise pode ocorrer entre 20 a $50 \mathrm{~g}$, quando se utiliza dialisato sem glicose ${ }^{(60)}$. A perda pode variar em decorrência do tipo de diálise, concentração de glicose no banho e dos níveis séricos de glicose. Ocorre também perda de vitaminas hidrossolúveis durante os procedimentos dialíticos, as quais podem ser administradas por meio de suplementação .

\section{SUPORTE NUTRICIONAL}

O momento de iniciar a terapia nutricional será influenciado pela doença de base, o grau de catabo- lismo protéico e pelo estado nutricional do paciente. Nos pacientes desnutridos ou catabólicos, a terapia nutricional deve ser utilizada, mas naqueles bem nutridos, e com condições de reiniciar a dieta normal em uma semana, não será necessário nenhum suporte nutricional, específico.

A infusão de grandes quantidades de aminoácidos e glicose, na fase inicial da IRA vinte e quatro (24) a quarenta e oito (48) horas após cirurgia ou trauma), pode aumentar o consumo renal de oxigênio, agravando a lesão tubular e a disfunção renal ${ }^{(75)}$.

\subsection{Suporte calórico e protéico}

A necessidade calórica do paciente com IRA depende da doença de base e do procedimento dialítico instituído. Geralmente, tem sido preconizado aporte calórico acima de $50 \mathrm{kcal} / \mathrm{kg} / \mathrm{dia}$. O gasto energético deve ser determinado por equações preditivas ou pela calorimetria indireta (Tabela VI).

Feita a determinação da necessidade calórica do paciente, faz-se a escolha dos alimentos a serem utilizados. Os carboidratos representam a principal

Tabela VI - Cálculo das necessidades calóricas diárias (adaptado de Monson \& Mehta ${ }^{(56)}$ ).

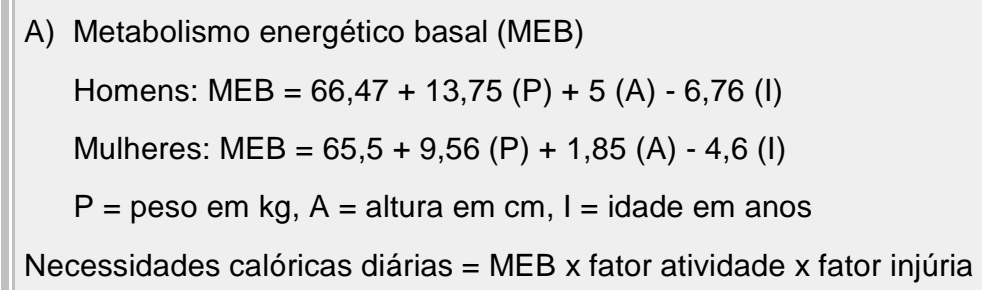

Fator atividade Fator injúria

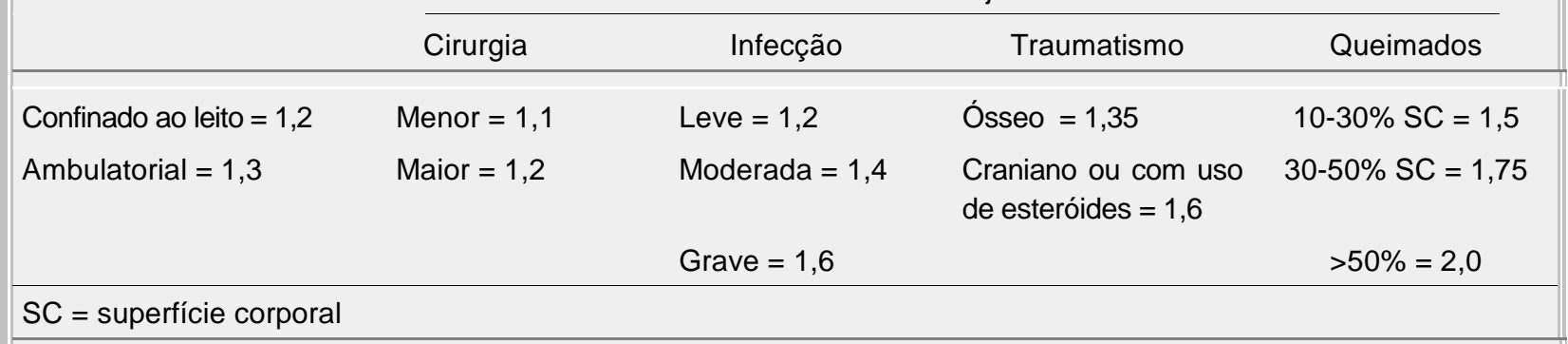

B) Metabolismo energético de carbono $\left(\mathrm{VCO}_{2} \mathrm{ml} / \mathrm{min}\right)$

Cálculo segundo a fórmula de Weir:

3,9 $\mathrm{VO}_{2}+1,1 \mathrm{VCO}_{2}=$ basal: método da calorimetria indireta

Medidas de:

- Consumo de oxigênio $\left(\mathrm{VO}_{2} \mathrm{ml} / \mathrm{min}\right)$

- Produção de dióxido kcal/min x 1440 = kcal/d 
fonte energética (55 a $65 \%$ do total), e os alimentos mais utilizados são arroz, batata e macarrão, os quais contêm, também, proteínas. Outras fontes de carboidratos são açúcares, doces e chocolates, mas os pacientes não devem ter glicemia e triglicérides aumentados. As gorduras representam 30 a $35 \%$ das calorias totais, sendo que pacientes com hipertrigliceridemia devem receber triglicérides de cadeia média. A quantidade de proteína a ser dada ao paciente é superior à que é dada ao portador de IRC $(0,6 \mathrm{~g} / \mathrm{kg} / \mathrm{dia})$, e aos indivíduos normais $(0,8 \mathrm{~g} / \mathrm{kg} / \mathrm{dia})$.

O cálculo deve ser individualizado de acordo com o grau de estresse metabólico, presente (Tabela VII).

Todo o nitrogênio derivado dos aminoácidos, liberado durante a degradação das proteínas, é convertido em uréia, e o grau de catabolismo protéico pode ser avaliado clinicamente pelo cálculo da taxa de aparecimento uréico (TAU).

TAU $(\mathrm{g} / \mathrm{dia})=\mathrm{UN}$ urinária $(\mathrm{g} / \mathrm{dia})+\mathrm{UN}$ do dialisado (g/dia) + Alteração da UN corporal (g/dia).

Alteração da uréia nitrogenada corporal (g/dia) $=\mathrm{UNS}_{\mathrm{f}}-\mathrm{UNS}_{\mathrm{i}}(\mathrm{g} / \mathrm{litro}) \times \mathrm{PC}_{1}(\mathrm{~kg} /$ dia $) \times 0,6+\left(\mathrm{PC}_{\mathrm{f}}\right.$ - $\left.\mathrm{PC}_{\mathrm{i}}\right) \times \mathrm{UNS}_{\mathrm{i}}(\mathrm{g} / \mathrm{litro}) \times(1$ litro/kg); onde i e f são os valores inicial e final ao período das medidas; UNS é a uréia nitrogenada do soro (g/litro); PC é o peso corporal (kg); 0,6 é uma estimativa da água corporal; e 1 é o volume de distribuição da uréia no aumento ou na perda de peso.
Os pacientes com TAU menor que $5 \mathrm{~g}$ acima da ingestão diária de nitrogênio, apresentam prognóstico excelente em relação à recuperação da função renal, e são, geralmente, portadores de IRA por nefrotoxinas (aminoglicosídeos, contrastes radiológicos, etc.).

Os pacientes com TAU que excede 5 a $10 \mathrm{~g}$ por dia apresentam catabolismo moderado, e estão complicados freqüentemente por infecção, peritonite, ou moderado grau de agressão (pós-operatório de grandes cirurgias). Suporte nutricional enteral e/ou parenteral pode ser necessário, além de diálise freqüente para evitar acúmulo de escórias nitrogenadas.

Nos pacientes com traumatismo grave, extensas áreas queimadas ou sepse, a TAU excede a ingestão nitrogenada por mais de $10 \mathrm{~g} / \mathrm{dia}$, e, nesses casos, o tratamento, geralmente inclui nutrição parenteral, suporte hemodinâmico e ventilatório e terapias dialíticas contínuas (HDAVC - Hemodiálise artériovenosa contínua ou HDVVC - Hemodiálise venovenosa contínua). Nesse grupo, a mortalidade é alta, podendo chegar a $80 \%$; mas o responsável pelo prognóstico ruim é a doença hipercatabólica subjacente.

\subsubsection{Vitaminas}

Vitaminas lipossolúveis - deve ser feita suplementação para pacientes que estão recebendo suporte nutricional por mais de duas semanas, e a reposição de vitamina A deve seguir o "Recommended Dietary

\begin{tabular}{|c|c|c|c|}
\hline \multicolumn{4}{|c|}{ Tabela VII - Avaliação do grau de catabolismo e plano de nutrição ${ }^{(75)}$} \\
\hline & \multicolumn{3}{|c|}{ Grau de catabolismo } \\
\hline & Baixo & Moderado & Alto \\
\hline UN (taxa/dia) & $<5 g$ & $5-10 \mathrm{~g}$ & $>20 \mathrm{~g}$ \\
\hline \multicolumn{4}{|l|}{ Recomendações } \\
\hline Proteína (g/kg/dia) & $0,5-0,8$ & $0,8-1,2$ & $1,5-2,5^{*}$ \\
\hline \multirow[t]{5}{*}{ Nutrientes } & Alimento & - & - \\
\hline & Fórmulas enterais & Fórmulas enterais & Fórmulas enterais \\
\hline & AAE (solução) & AAE + AANE (solução) & AAE + AANE (solução) \\
\hline & & Glicose 50 a $70 \%$ & Glicose 50 a $70 \%$ \\
\hline & & Emulsão lipídica 20\% & Emulsão lipídica 20\% \\
\hline Via & Oral, enteral ou parenteral & Enteral e/ou parenteral & Enteral e/ou parenteral \\
\hline $\begin{array}{l}\text { UN = uréia nitrogenad } \\
{ }^{\star} \text { Pacientes em terapia }\end{array}$ & $\begin{array}{l}\text { ninoácidos essenciais, AANE = } \\
\text { tínua. }\end{array}$ & aminoácidos não essenciais. & \\
\hline
\end{tabular}


Allowance" (RDA), 1000 mcg para homens e $800 \mathrm{mcg}$ para mulheres. A reposição de vitamina D não está bem estabelecida.

Vitaminas hidrossolúveis - ocorrem perdas dessas vitaminas durante a terapia dialítica, e a recomendação é a mesma que para pacientes renais crônicos, ou seja, $10 \mathrm{mg} / \mathrm{d}$ de vitamina $\mathrm{B} 6,1 \mathrm{mg} / \mathrm{d}$ de folato e $100 \mathrm{mg} / \mathrm{d}$ de vitamina $\mathrm{C}$.

\section{DIÁLISE}

Apesar dos consideráveis avanços no tratamento dialítico, nas últimas décadas, o prognóstico de pacientes com IRA, necessitando de tratamento dialítico, continua sombrio, com taxas de mortalidade freqüentemente superiores a 50\% (42 a 75\%). O momento ideal para iniciar o tratamento dialítico dos pacientes portadores de IRA, e o método dialítico a ser utilizado depende das características clínicas do paciente; do tipo e da gravidade da IRA; e da experiência do nefrologista e dos equipamentos disponíveis para implementá-lo.

\subsection{Diálise peritoneal}

Durante muitos anos, a diálise peritoneal (DP) foi reservada para tratamento da IRA e para pacientes aguardando transplante renal. Atualmente, ela é usada principalmente no tratamento de pacientes renais crônicos, mas ainda permanece uma ferramenta no manejo da IRA. Há muitas razões para se manter o uso da DP no tratamento da IRA, principalmente pela sua simplicidade e larga aplicabilidade. A DP pode ser realizada em qualquer hospital com o uso de técnicas manuais, e o acesso peritoneal pode ser facilmente realizado pela inserção de um cateter agudo, semi-rígido ou um cateter de Tenckhoff com "cuff" único.

A DP, por não necessitar de anticoagulação sistêmica, é indicada no tratamento de pacientes com IRA no período pós-operatório imediato e no daqueles com trauma grave, hemorragia intracerebral, e estados de hipocoagulabilidade. Em decorrência da correção gradual do desequilíbrio eletrolítico e remoção das escórias nitrogenadas, a DP raramente resulta em síndrome do desequilíbrio. Pelo mesmo motivo, a DP é mais indicada para o tratamento de pacientes com o sistema cardiovascular instável, o que é característico dos pacientes com IRA no período pós-operatório.

Finalmente, a DP tem se mostrado conveniente e satisfatória para o tratamento de crianças com IRA, em decorrência da dificuldade de se conseguir acesso vascular ${ }^{(76)}$.

\subsubsection{Uremia}

O quadro clínico de uremia, no curso da IRA, é uma das principais razões para início da terapia dialítica.

Nos pacientes com IRA e serosite urêmica, a indicação da DP pode ser conveniente, pois prescinde de anticoagulação. Nos pacientes com hipercatabolismo, ou seja, quando se observam aumentos diários dos níveis de uréia plasmática de 60 a $100 \mathrm{mg} / \mathrm{dl} / \mathrm{dia}$, a DP pode ser ineficaz, pois, não consegue remover a uréia e outras escórias nitrogenadas na mesma proporção. Entretanto existem medidas que, individualmente, podem aumentar o "clearance" peritoneal de solutos em até $25 \%$ tais como: administração de vasodilatadores intraperitoneais como nitroprussiato de sódio (4 a $5 \mathrm{mg} / \mathrm{litro}$ ); trocas rápidas da solução dialisadora com fluxo de quatro (4) litros/hora; aumento do volume da solução de dois (2) para três (3) litros por troca; e aumento da ultrafiltração osmótica (> concentração de glicose).

\subsubsection{Hipercalemia}

A DP tem eficiência limitada na remoção de potássio do organismo, quando comparada com outros métodos. O uso das resinas (30g) de troca iônica (Kayexalate, Sorcal) removem cerca de $30 \mathrm{mEq} / \mathrm{h}$ de potássio do organismo, enquanto apenas $12 \mathrm{mEq} / \mathrm{h}$ são retirados pela DP, que retira $20 \%$ menos que a hemodiálise ${ }^{(77)}$.

\subsubsection{Hipervolemia}

A DP é menos eficiente do que a hemodiálise, na remoção de volume, porém causa menor estresse hemodinâmico e pode gerar taxa de ultrafiltração elevada. Nos casos de insuficiência cardíaca congestiva descompensada, complicada com IRA, a DP apresenta a vantagem de gerar balanço hídrico negativo, sem indução de instabilidade hemodinâmica. Pode-se retirar até $700 \mathrm{ml} / \mathrm{h}$, realizando duas trocas de solução dialisadora com glicose a $4,25 \%$. Na insuficiência hepática crônica ou na síndrome hepatorrenal, associada à hepatite fulminante, evoluindo com IRA reversível, a DP está indicada. Nesses casos, existem alguns benefícios: menor risco de sangramento, estabilidade hemodinâmica, controle metabólico adequado da hiponatremia e da hipoglicemia e controle da ascite. 


\subsubsection{Acidose}

Embora a DP tenha uma eficiência cinco vezes inferior à da hemodiálise, nos pacientes em tratamento hemodialítico crônico, os níveis séricos de bicarbonato são inferiores àqueles mantidos em diálise peritoneal contínua ambulatorial. Nos pacientes hipercatabólicos, com acidose metabólica, a hemodiálise permite melhor controle do equilíbrio acidobásico.

De maneira geral, a DP apresenta simplicidade técnica e segurança, e sua indicação na IRA deve se basear em suas características principais:

- excelente tolerância cardiovascular;

- não necessita de anticoagulação;

- baixo risco de síndrome do desequilíbrio.

\subsection{HEMODIÁLISE E TERAPIAS CONTÍNUAS}

\subsubsection{Acesso vascular}

O paciente portador de IRA, para se submeter a tratamento dialítico, necessita, inicialmente, de um acesso vascular, o qual, habitualmente, é temporário. Os métodos para estabelecer esse acesso envolvem a punção percutânea de um grande vaso sangüíneo (jugular interna, subclávia e femoral) ${ }^{(25)}$. Os cateteres venosos de duplo lúmen são os mais utilizados, porém são calibrosos e apresentam risco de trombose ou estenose tardia da veia subclávia ${ }^{(78)}$.

Outra via de acesso que podemos utilizar é a introdução de cateteres menos calibrosos, por punção percutânea, na artéria e veia femorais. Esta punção apresenta alto fluxo sanguiíneo, baixa incidência de coagulação e infecção local, porém exige confinamento do paciente ao leito ${ }^{(78)}$.

Outra via de acesso são os "shunts" arteriovenosos ("shunt" de Quinton-Scribner, "shunt" A-V), que são realizados através da inserção cirúrgica de um par de cânulas, conectando uma artéria e uma veia das extremidades (antebraço ou perna), formando uma fístula externa. Apresentam baixo risco de sangramento, mas exigem implante cirúrgico e altos riscos de coagulação e infecção, o que os torna pouco utilizados, no momento.

\subsubsection{Dialisador}

Existem dois modelos básicos de dialisadores: placas paralelas e capilares de fibras ocas, e é onde ocorrem as trocas por difusão e a ultrafiltração do plasma. Na construção desses dialisadores, são usados três tipos de membranas: celulose, celulose modificada e sintética. A celulose é obtida pelo processamento do algodão e, até recentemente, o tipo de membrana mais utilizado nos dialisadores era o cuprofane.
As membranas sintéticas incluem a poliacrilonitrila (PAN), a polissulfona, a poliamida, o policarbonato e o polimetilmetacrilato, e são mais permeáveis a moléculas médias e grandes do que o cuprofane, além de serem mais biocompatíveis. O tratamento dos pacientes portadores de IRA não oligúrica com membranas biocompatíveis tem sido motivo de investigação para verificar se apresentam vantagens ou não ${ }^{(79)}$. As membranas de cuprofane promovem efeito adverso na recuperação da função renal de animais com IRA experimental, especialmente por ativação do complemento e infiltração neutrofílica do parênquima renal $^{(80)}$. Os produtos da ativação do complemento promovem vasoconstrição direta e indiretamente, enquanto os neutrófilos ativados secretam substâncias vasoconstritoras que intensificam a isquemia, particularmente na medula renal.

Esses dados sugerem que o uso de membranas mais biocompatíveis pode beneficiar a evolução dos pacientes portadores de IRA sem oligúria ou anúria. Entretanto, devemos ter em conta que outros fatores que não a membrana dialisadora podem afetar a evolução desses doentes, e os critérios utilizados para selecioná-los em grupos com grau de gravidade semelhante não são ainda os ideais ${ }^{(81)}$.

\subsubsection{Anticoagulação}

A anticoagulação é obtida com o uso da heparina. A dose recomendada é de $100 \mathrm{U} / \mathrm{kg}$ de peso, no início da diálise, e $20 \mathrm{U} / \mathrm{kg}$ de peso a cada hora de diálise, até uma hora antes de seu término. Pode ser substituída pelo uso contínuo de uma solução de $100 \mathrm{U}$ de heparina por quilo de peso, diluída em $50 \mathrm{ml}$ de solução fisiológica, infundida a uma velocidade de $0,25 \mathrm{ml}$ de solução por minuto. Caso o fluxo sangüíneo seja inferior a $100 \mathrm{ml} / \mathrm{min}$ deve-se fazer uma anticoagulação mais agressiva para evitar coagulação do sistema extracorpóreo. O tempo de coagulação deve ser controlado (TTPA ou Lee-White), pois os pacientes apresentam resposta anticoagulante diferente.

Para pacientes com risco de sangramento, podemos utilizar a heparinização regional ou doses mínimas de heparina, mas para aqueles que apresentam alto risco de sangramento o melhor é fazer hemodiálise sem qualquer anticoagulante, entretanto será necessário que exista fluxo sangüíneo igual ou superior a $150 \mathrm{ml} / \mathrm{min}$. O uso de heparina de baixo peso molecular (enoxaparina) pode ser útil nestes pacientes, visto não interferir intensamente com a coagulação normal do paciente. 


\subsection{HEMODIÁLISE INTERMITENTE}

$\mathrm{Na}$ hemodiálise intermitente, o transporte de solutos se dá de acordo com o movimento difusional passivo, obedecendo ao gradiente de concentração entre o sangue e a solução dialisadora. A uréia, creatinina e potássio movem-se do sangue para a solução dialisadora e o cálcio e o bicarbonato movem-se no sentido contrário. O fluxo sangüíneo ocorre em sentido contrário ao da solução dialisadora, o que permite maior área de trocas difusionais. A quantidade de solutos retirados por difusão depende da área da superfície de trocas da membrana e dos fluxos de sangue e da solução dialisadora.

A hemodiálise intermitente está indicada em todos os pacientes com IRA que se apresentem hemodinamicamente estáveis, e pode ser feita diariamente ou em dias alternados para manter o balanço hídrico e controlar a geração de uréia, naqueles pacientes que estão evoluindo com hipercatabolismo. A necessidade de retirada de grandes volumes em curto espaço de tempo \{quatro (4) horas \} acaba causando episódios de hipotensão arterial. Para minimizar esses episódios, pode-se efetuar, inicialmente, ultrafiltração isolada, seguida de hemodiálise com pouca ou nenhuma retirada de água.

A utilização de banho de diálise com bicarbonato no lugar de acetato também oferece uma segurança adicional, mas não evita totalmente os aciden- tes hipotensivos. Banho com contéudo de sódio variável (133 a $150 \mathrm{mEq} / \mathrm{l})$ também está associado à maior estabilidade hemodinâmica, durante a hemodiálise.

\subsection{TERAPIAS DE SUBSTITUIÇÃO RENAL CON- TÍNUAS ${ }^{(82)}$}

\subsubsection{Ultrafiltração lenta contínua (UFCL)}

O acesso vascular pode ser arteriovenoso ou venovenoso, e o filtro utilizado pode ser de diferentes permeabilidades. Esta terapia está indicada para controle volêmico, e o "clearance" de solutos é mínimo, não havendo reposição do volume ultrafiltrado. Ela é freqüentemente utilizada junto com a hemodiálise convencional para evitar a remoção de fluidos durante o procedimento difusivo da hemodiálise. A ultrafiltração lenta contínua é usada em pacientes no pósoperatório de cirurgias cardíacas com sobrecarga volêmica e em outros pacientes, para permitir o uso seguro de soluções intravenosas tais como hiperalimentação.

\subsubsection{Hemodiálise arteriovenosa contínua (HDAVC)}

É uma forma de hemodiálise lenta que utiliza fluxo sangüíneo arteriovenoso reduzido (fluxo de 50 a $200 \mathrm{ml} / \mathrm{min}$, dependente da pressão arterial média do paciente) e um pequeno fluxo de solução de diálise (1 a 2 litros/h de solução de diálise peritoneal com glicose a $1,5 \%$ ) (Figura 1). Pode ser realizada durante

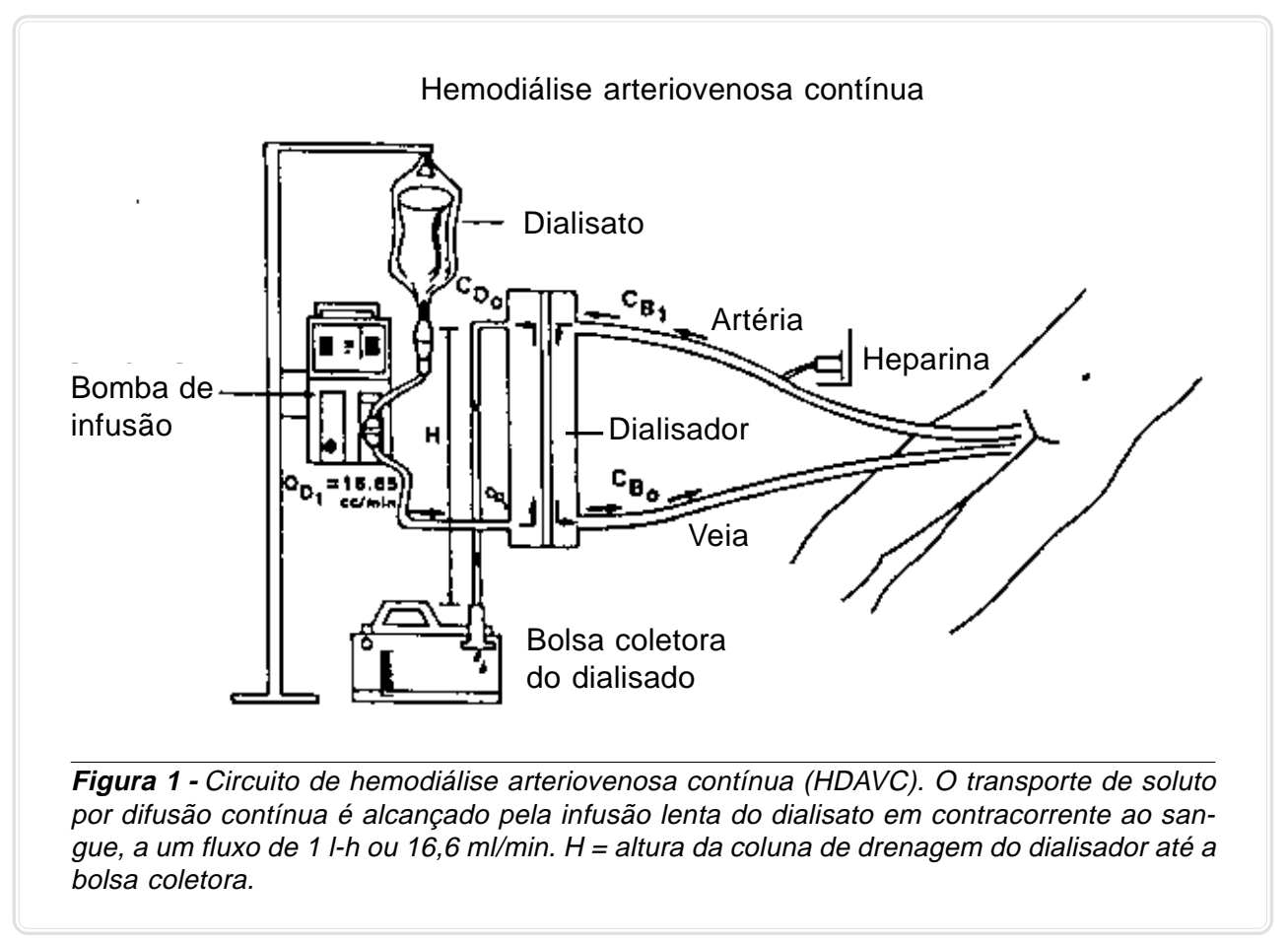


vinte e quatro (24) horas por dia, durante vários dias seguidos. A retirada de solutos é feita por difusão e a retirada de fluídos, por convecção. A via de acesso pode ser o "shunt" arteriovenoso ou a canulação concomitante da artéria e veia femoral. O ritmo de ultrafiltração dependerá das seguintes variáveis: pressão hidrostática do sangue no interior do dialisador, altura da coluna de drenagem da solução de diálise, da osmolaridade da solução de diálise e da pressão oncótica do plasma.

\subsubsection{Hemodiálise venovenosa contínua (HDVVC)}

É um procedimento semelhante à hemodiálise arteriovenosa contínua, exceto que necessita de uma bomba de sangue para manter o fluxo sangüíneo, obtido por cateteres inseridos em veias profundas (Figura 2). Como utiliza bomba de sangue, pode ocorrer embolia gasosa e torna-se necessário o uso do detetor de bolhas.

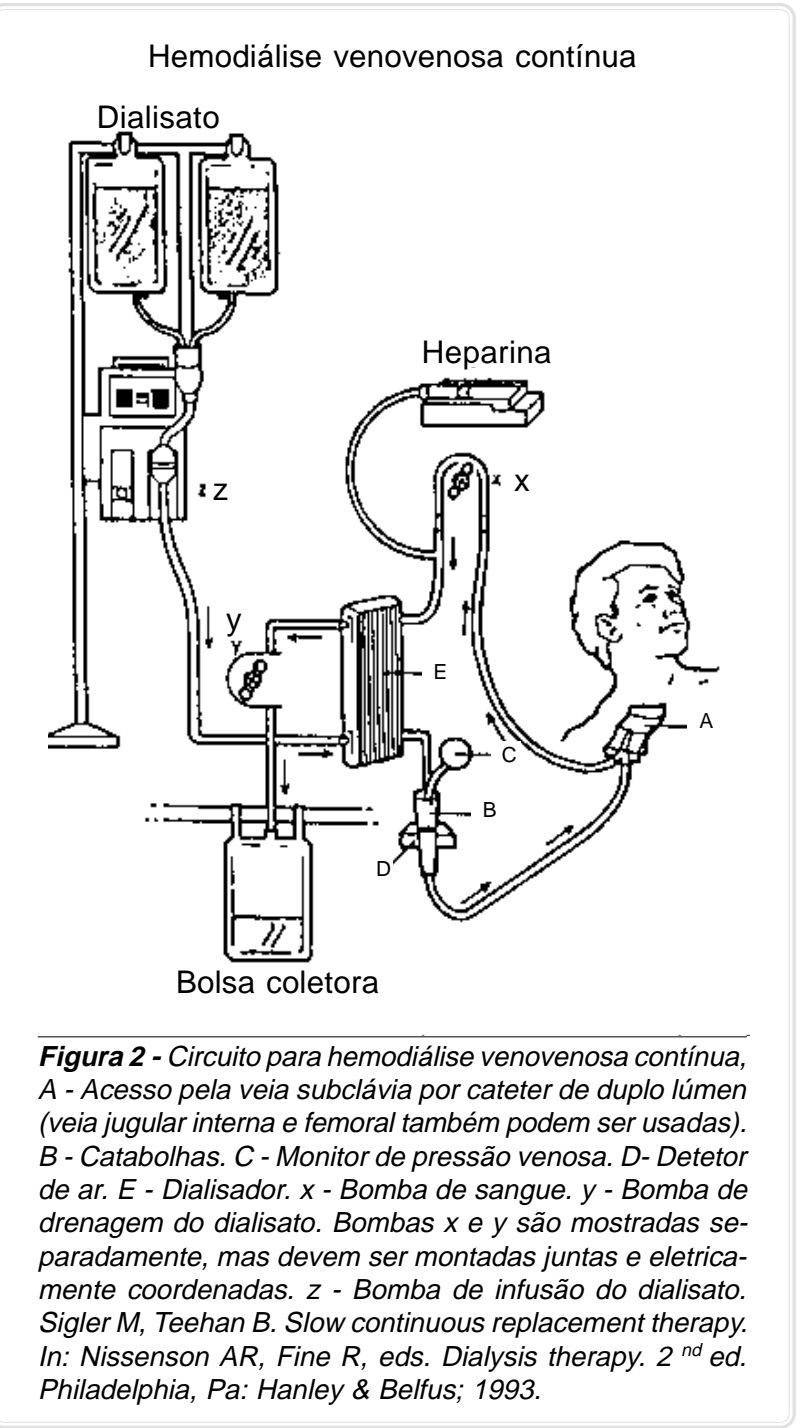

\subsubsection{Hemofiltração arteriovenosa contínua (HAVC)}

Um hemofiltro de baixa resistência é interposto entre uma via arterial e venosa, sem a necessidade de bomba de sangue. $\mathrm{O}$ acesso vascular pode ser obtido através de um "shunt" arteriovenoso, ou cateteres implantados por punção percutânea da artéria e veia femorais. Em conseqüência da diferença de pressão arteriovenosa, o sangue entra no hemofiltro, onde ocorre a ultrafiltração. A heparina é administrada por uma bomba de infusão, para evitar a coagulação do sistema. O ultrafiltrado flui para um coletor graduado, onde é feita a aferição horária, numa taxa de filtração de 20 a $30 \mathrm{ml} / \mathrm{min}$. A pressão de filtração depende da posição do coletor abaixo do capilar e da pressão positiva, exercida pelo sangue. $\mathrm{O}$ fluxo sangüíneo é determinado pela pressão arterial média. A reposição de fluídos pode ser feita na linha arterial, antes do filtro (HAVC pré-dilucional) ou na linha venosa, após o filtro (HAVC pós-dilucional). A hemofiltração arteriovenosa contínua utiliza filtro de alta permeabilidade (hemofiltro), e o gradiente de pressão arteriovenoso do paciente para impulsionar o sangue (Figura 3). A HAVC é um processo contínuo de remoção de líquiido e substâncias urêmicas por convecção. Nesse método, há necessidade de retirada e de reposição de grandes volumes de líquiido. Esta técnica é útil para manter o paciente "seco", preservando a estabilidade hemodinâmica, porém é insuficiente para manter o controle adequado do nível de uréia em pacientes hipercatabólicos, pois o "clearance" médio de uréia, na HAVC, é em torno de $10 \mathrm{ml} / \mathrm{min}$.

\subsubsection{Hemofiltração venovenosa contínua (HVVC)}

Esse processo é semelhante à hemofiltração arteriovenosa contínua, utilizando, entretanto, a assistência de uma bomba para manter o fluxo sangüíneo efetivo, no sistema extracorpóreo, após canulização de veias centrais (femoral, subclávia ou jugular), geralmente com cateteres de duplo lúmen.

\subsubsection{Hemodiafiltração arteriovenosa contínua (HDFAVC)}

Neste procedimento, combina-se a técnica de depuração por convecção, descrita na HAVC e na HVVC, com um elemento de difusão (diálise), tornando-se mais efetiva na remoção de catabólitos sangüíneos. A via de acesso é um "shunt" arteriovenoso ou a colocação de cateteres na artéria e veia femoral. 


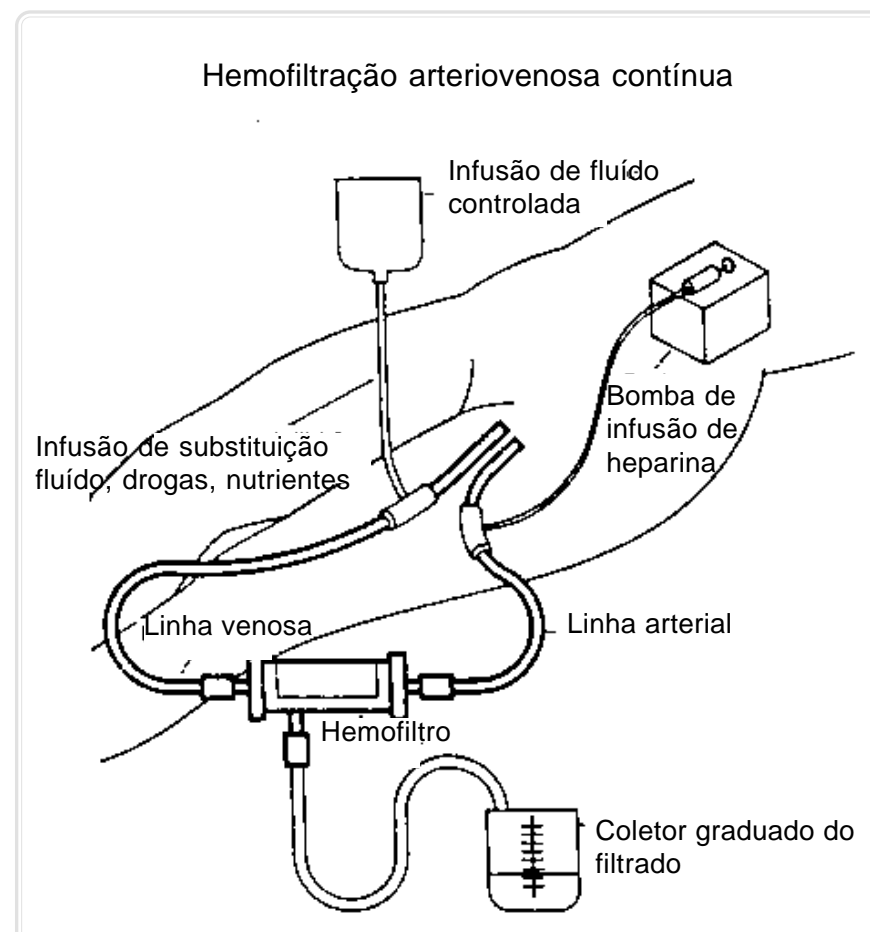

Figura 3 - Circuito para hemofiltração arteriovenosa contínua (HAVC). O acesso é feito via cateterização da artéria e veia femoral. O líquido de reposição é infundido distalmente ao hemofiltro (pós-filtro).

$\mathrm{Na}$ execução deste procedimento, utilizam-se filtros e linhas de alto custo, além de ser procedimento complexo, que pode ocasionar problemas graves, se for realizado por pessoal sem experiência com a terapêutica hemodialítica.

\subsubsection{Hemodiafiltração venovenosa contínua (HDFVVC)}

Esta técnica dialítica é semelhante à anterior, mas é necessário o uso de bomba de sangue no sistema extracorpóreo, o que torna este procedimento mais efetivo e constante, pois mantém um fluxo de sangue sempre próximo do ideal. A via de acesso é a colocação de cateteres por punção em veias profundas (jugular, subclávia ou femoral).

\subsubsection{Hemofiltração intermitente (HFI)}

A hemofiltração intermitente consiste na retirada de grandes volumes de ultrafiltrado plasmático, com a infusão quase proporcional de um fluido isotônico padrão, em um período curto de tempo \{três (3) a seis (6) horas, em média\}, usando um filtro com membranas de alta capacidade de ultrafiltração, o qual, normalmente, é realizado todo dia. Os filtros e o líqüido de reinfusão são de alto custo.

\section{COMPLICAÇÕES MAIS FREQÜENTES}

\subsection{Infecções}

São as causas mais freqüentes de complicações nos pacientes com IRA, principalmente nos casos de pós-operatório. São também a causa mais freqüente de óbito. As infecções mais comuns são as pulmonares, urinárias e sepse $(80 \%, 60 \% \text { e } 30 \% \text {, respectivamente })^{(83)}$. Os cateteres venosos, arteriais e vesicais, bem como o acesso vascular para tratamento dialítico se tornam as portas de entrada mais freqüentes dos agentes infecciosos.

\subsection{Complicações cirúrgicas}

Pacientes que desenvolvem IRA pós-cirurgia têm uma alta incidência de complicações, geralmente difíceis de diagnosticar, que ocorrem em $33 \%$ dos casos e com $83 \%$ de mortalidade $^{(83)}$.

\subsection{Complicações gastrintestinais}

O sangramento gastrintestinal não é tão freqüiente, se o paciente estiver bem dialisado. Os bloqueadores de secreção gástrica têm sua utilidade na profilaxia desses sangramentos. Freqüentemente os pacientes estão anoréticos e podem apresentar náuseas e vômitos.

\subsection{Outras complicações}

Insuficiência cardíaca por retenção de líquidos, confusão mental, convulsões, etc.

\subsection{Utilização de drogas}

Deve-se considerar que, tanto em casos de IRA oligúrica como não oligúrica, a depuração da creatinina está, geralmente, abaixo de $10 \mathrm{ml} / \mathrm{min}$ e a correção das dosagens deve ser feita de acordo com esse parâmetro, evitando a utilização dos valores da creatinina sérica para cálculos do ajuste de drogas.

\section{EVOLUÇÃO E RECUPERAÇÃO}

A evolução clínica da NTA é dividida em fases oligúrica, diurética e de recuperação. Essas fases não se aplicam para uma grande proporção de NTA não oligúrica. A duração da oligúria pode ser pequena, de algumas horas até semanas ou meses com média de dez (10) a catorze (14) dias. O início da fase diurética é sinalizado pelo aumento progressivo da diurese acima de $400 \mathrm{ml} /$ dia, ocasionalmente, de uma 
poliúria, que é mais difícil de ocorrer, se houver balanço hídrico adequado, e uma diálise prévia, eficaz. $\mathrm{O}$ modo mais simples de manuseio de uma diurese intensa, caso venha a ocorrer, é a reposição com solução salina a $0,45 \%$, geralmente num volume total de $2 / 3$ da diurese total de vinte e quatro (24) horas, até que os níveis de uréia caiam abaixo de $120 \mathrm{mg} \%$. Abaixo desse nível, mesmo com balanço negativo, deixa-se o paciente livre para ingerir líquidos pelo controle da sede ou administram-se $2000 \mathrm{ml}$ por dia, como se fosse para um paciente com função renal normal que estivesse em jejum $^{(17)}$.
Normalmente, os níveis de uréia e creatinina continuam a se elevar alguns dias após o início da diurese mantida acima de $1000 \mathrm{ml} / \mathrm{dia}$. Nessa fase, existe ainda a possibilidade de ocorrerem várias complicações como: infecções, sangramento gastrintestinal, convulsões, distúrbios hidroeletrolíticos.

Apesar da gravidade e das altas taxas de mortalidade, que é maior nos casos pós-cirúrgicos, a NTA é uma doença potencialmente reversível, não havendo como prever qual paciente se beneficiará do tratamento, que deve ser agressivo para todos, enfatizando a importância da profilaxia e tratamento precoce.

COSTA JAC da, MOYSES NETO M \& VIEIRA NETO OM. Acute renal failure in intensive care unit. Medicina, Ribeirão Preto, 31: 532-551, oct./dec. 1998.

ABSTRACT: In hospitalized patients, acute renal failure(ARF) has an incidence from $2 \%$ to $5 \%$, mostly due to: septic shock, hypovolemia, aminoglycoside use, cardiac failure and radiocontrast media. Some of these patients are in the intensive care unit (ICU) and show high rates of mortality despite the advances of treatment. In this paper, we discuss the most common causes of ARF, emphasizing prevention in the hospitalized patients and the importance of the differencial diagnosis between pre-renal and renal causes of ARF. Among the renal causes, acute tubular necrosis (ATN) has a high incidence provoked by either hypoperfusion and/or exogen and endogen nephrotoxins. Hydro-eletrolytic balance, nutritional assessment and dialysis are the main topics to be considered in the treatment. The dialytic treatment, when required, can be instituted as peritoneal dialysis, hemodialysis and the continuous renal replacement methods of therapy.

UNITERMS: $\quad$ Dialysis. Kidney Failure, Acute. Kidney Tubular Necrosis, Acute.

\section{REFERÊNCIAS BIBLIOGRÁFICAS}

1 - ANDERSON RJ; ROSEN S \& EPSTEIN FH. Acute renal failure. In: SCHRIER RW \& GOTTSCHALK CW. Diseases of the kidney. $4^{\text {th }}$ ed. Little Brown., Boston, p. 1413-1446,1988.

2 - HOU SH et al. Hospital-acquired renal insufficiency: a prospective study. Am J Med 74: 243-248,1983.

3 - HUMES HD. Aminoglycoside nephrotoxicity. Kidney Int 33: 900-908,1988.

4 - SHUSTERMAN N et al. Risk factors and outcome of hospital-acquired acute renal failure. Am J Med 74: 243-248, 1987.

5 - WILKINS RG \& FARAGHER EB. Acute renal failure in na intensive care unit: incidence, prediction and outcome. Anaesthesia 38: 628-634,1983.

6 - SCHWILK B et al. Epidemiology of acute renal failure and outcome of haemodiafiltration in intensive care. Intensive Care Med 23: 1204-1211, 1997

7 - NAIR P \& BIHARI D. Acute renal failurer in the ICU in the 1990s - "anything goes"?.Intensive Care Med 23: 1193-1196, 1997.
8 - MEMBERS OF THE AMERICAN COLLEGE OF CHEST PHYSICIANS. Society of Critical Care Medicine Consensus Conference Comittee. Definitions for sepsis and organ failure and guidelines for the use of innovative therapies in sepsis. Crit Care Med 20: 864-874, 1992.

9 - KNAUS WA \& WAGNER DP. Multiple systems organ failure: epidemiology and prognosis. Crit Care Clin 5: 221-232, 1989.

10 - COSENTINO F; CHAFF C \& PIEDMONTE M. Risk factors influencing survival in ICU acute renal failure. Nephrol Dial Transplant 9: 179-182, 1994. Suppl. 4.

11 - BRIVET F et al. On behalf of the French Study group on acute renal failure. Acute renal failure in intensive care units - causes, outcomes and prognostic factors of hospital mortality: a prospective multicenter study. Crit Care Med 24: 192-198,1996.

12 - FABER MD et al. The differencial diagnosis of acute renal failure. In: LAZARUS JM \& BRENNER BM. Acute renal failure, $3^{\text {th }}$ ed., Churchill Livingstone, New York, p. 133-192, 1993.

13 - GILLIUM D; CONGER JD \& ANDERSON RJ. Acute renal failure. In: SUKI WN \& MASSRY SG. Therapy of renal diseases and related disorders, $2^{\text {nd }}$ ed., Kluwer Academic Publishers, Norwell, Massachusetts, p. 285-303, 1991 
14 - MINDELL JÁ \& CHERTOW GM. A practical approach to acute renal failure. Med Clin North Am 81: p. 731-748, 1997.

15 - BURNNET Jr JC. Acute renal failure associated with cardiac failure and hypovolemia. In: LAZARUS JM \& BRENNER $B M$. Acute renal failure, $3^{\text {th }}$ ed, Churchill Livingstone, New York, p. 193-206, 1993.

16 - McLLINES EG et al. Renal failure in the elderly. Quart $\mathbf{J}$ Med 64: 583-588,1987.

17 - BREZIS M; ROSEN S \& EPSTEIN FH. Acute renal failure due to ischemia (acute tubular necrosis). In: LAZARUS JM $\&$ BRENNER BM. Acute renal failure, $3^{\text {th }}$ ed; Churchill Livingstone, New York, p. 207-229, 1993.

18 - FOTINO S \& SPORN P. Non-oliguric acute renal failure after captopril therapy. Arch Intern Med 143: 1252-1257, 1983.

19 - BREZIS M; ROSEN S \& EPSTEIN FH.Acute renal failure. In: BRENNER BM \& RECTOR FC. The kidney, $4^{\text {th }}$ ed, W.B.Saunders, Philadelphia, p. 993-1112, 1991.

20 - THADANI R; PASCUAL M \& BONVENTRE JV. Acute renal failure. N Engl J Med 334: 1448-1453, 1996.

21 - SWAN SK \& BENNET WM. Nephrotoxic acute renal failure. In: LAZARUS JM \& BRENNER BM. Acute renal failure, $3^{\text {th }}$ ed, Churchill Livingstone, New York, p. 237-392, 1993.

22 - PALLER MS. Drug induced nephropathies. Med Clin North Am 74: 909-917,1990.

23 - EISENBERG JM et al. What is the cost of nephrotoxicity associated with aminoglycosides? Ann Intern Med 107: 900-909, 1987.

24 - COGGINS CH \& FANG LST. Acute renal failure associated with antibiotics, anesthetics agents, and radiographic contrast agents. In: BRENNER BM \& LAZARUS JM. Acute renal failure, $2^{\text {nd }}$ ed, Churchill Livingstone, New York, p. 177-232, 1988.

25 - BERNS AS. Nephrotoxicity of contrast media. Kidney Int 36: 730-740, 1989.

26 - PARFREY PS; GRIFFITHS SM \& BARRET BJ. Contrast material-induced renal failure in patients with diabetes mellitus, renal insufficiency, or both. N Engl J Med 320: 143-148, 1989.

27 - SOLOMON R. Contrast-medium- induced acute renal failure. Kidney Int 53: 230-242, 1998.

28 - MORCOS SK \& NAHAS AM. Advances in the understanding of the nephrotoxicity of radiocontrast media. Nephron 78 :249-252, 1998.

29 - BROOKS PM \& DAY RO. Nonesteroidal antiinflamatory drugs difference and similarities. N Engl J Med. 324: 1716-1725, 1991.

30 - DUBROW A \& FLAMENBAUN W. Acute renal failure associated with myoglobinuria and hemoglobinuria. In: BRENNER BM \& LAZARUS JM. Acute renal failure, $2^{\text {nd }}$ ed, Churchill Livingstone, New York, p. 279-293, 1988.

31 - DON BR; RODRIGUEZ RA \& HUMPHREYS MH. Acute renal failure associated with pigmenturia or crystal deposits. In: SCHRIER RW \& GOTTSCHALK CW . Diseases of the kidney, $6^{\text {th }}$ ed, Litlle Brown, Boston, p. 1273-1302, 1996.
32 - ODEH M. The role of reperfusion-induced in the pathogenesis of the crush syndrome. N Engl J Med 324: 1417-1422, 1991

33 - DESFORGES JF. Early management of shock and prophylaxis of acute renal failure in traumatic rhabdomyolisis. $\mathbf{N}$ Engl J Med 322: 825-828, 1990.

34 - ANDERSON RJ et al. Non-oliguric acute renal failure. $\mathbf{N}$ Engl J Med 296: 1134-1138, 1977.

35 - DIXON BS \& ANDERSON RJ. Nonoliguric acute renal failure. Am J Kidney Dis 2: 71-80, 1985.

36 - FINN WF. Diagnosis and management of acute tubular necrosis. Med Clin North Am 74: 873-891,1990.

37 - MILLER TR et al. Urinary diagnostic indices in acute renal failure.Ann Intern Med 89: 47-50,1978

38 - ANDERSON RJ \& SCHRIER RW. Acute renal failure. In: SCHRIER RW, \& GOTTSCHALK CW . Diseases of the kidney, $6^{\text {th }}$ ed, Litlle Brown, Boston, p. 1069-1114,1996.

39 - DAVIDSON WD. Differencial diagnosis and treatment of acute renal failure. In: BRICKER NS \& KIRSCHENBAUN MA. The kidney: diagnosis and management, John Wiley, New York, p. 289-302, 1984.

40 - CAMERON JS. Acute renal failure in the intensive care unit today. Intensive Care Med 12: 64-70, 1986.

41 - CONGER J. Prophylaxis and treatment of acute renal failure by vasoactive agents: the fact and the myths. Kidney Int 53: S23-S26, 1998. Suppl. 64

42 - CONGER J. Drug therapy in acute renal failure. In: LAZARUS JM \& BRENNER BM. Acute renal failure, $3^{\text {rh }}$ ed, Churchill Livingstone, New York, p. 527-552,1993.

43 - LEVINSKY NG \& BERNARD DB. Mannitol and loop diuretics in acute renal failure. In: BRENNER BM \& LAZARUS JM. Acute renal failure, $2^{\text {nd }}$ ed, Churchill Livingstone, New York, p. 841-856, 1988.

44 - CANTAROVICH $\mathrm{F}$ et al. Furosemide in high doses in the treatment of acute renal failure. Postgrad Med J: p. 13-17, april 1971. Suppl. 47

45 - CANTAROVICH F et al. High dose furosemide in established acute renal failure. B M J 4: 449-450,1973

46 - BROWN CB; OGG CS \& CAMERON JS. High dose furosemide in acute renal failure: a controlled trial. Clin Nephrol 15: 90-96,1981.

47 - SHILLIDAY IR; QUINN KJ \& ALISON ME. Loop diuretics in the management of acute renal failure: a prospective, doubleblind, placebo-controlled, randomized study. Nephrol Dial Transplant 12: 2592-2596, 1997.

48 - LINDNER. Synergism of dopamine and furosemide in diureticresistant oliguric renal failure. Nephron 33: 121-126, 1983.

49 - LUMIERTGUL D et al. Furosemide and dopamine in malaria acute renal failure. Nephron 52: 40-46,1989.

50 - DENTON MD; CHERTOW GM \& GRADY HR. "Renal dose" dopamine for the treatment of acute renal failure: Scientific rationale, experimental studies and clinical trials. Kidney Int 49: 4-14,1996. 
51 - LEE MR. Dopamine and the kidney: tem years on. Clin Sci 84: 357-375, 1993.

52 - BONDE $J$ et al. Low dose dopamine in surgical and intensive care unit patients. Acta Anaesthesiol Scand 40: 326-330,1996.

53 - BRADY HR; BRENNER BM \& LIEBERTHAL W. Acute renal failure. In: BRENNER BM. The kidney, $5^{\text {th }}$ ed, W.B.Saunders, Philadelphia p. 1200-1252, 1996.

54 - HALPERIN ML \& JUNGAS RL. Metabolic production and renal disposition of hydrogen ions.: Kidney Int 24: 709-713, 1983.

55 - McCARRON DA et al. Severe mixed metabolic acidosis secondary to rhabdomyolisis. Am J Med 67: 905-908, 1979.

56 - MONSON P \& MEHTA RL. Nutrition in acute renal failure: a reappraisal for the 1990s. J Renal Nutr 4: 58-77, 1994.

57 - MASSRY SG et al. Divalent ion metabolism in patients with acute renal failure. Kidney Int 5: 437-445, 1974.

58 - GROSSMAN R A et al. Non-traumatic rhabdomyolisis and acute renal failure. N Engl J Med 291: 807-811, 1974.

59 - VANYPERSELE DE \& STRIHOW C. Potassium homeostasis in renal failure. Kidney Int 11: 491-504, 1977.

60 - WOLFSON M \& KOPPLE JD. Nutritional management of acute renal failure. In: LAZARUS JM \& BRENNER BM. Acute renal failure. $3^{\text {th }}$ ed. Churchill Livingstone, New York, $p$. 467-485, 1993.

61 - WINDSOR JA; KNIGHT GS \& HILL GL. Wound healing response in surgical patients. Recent food intake is more important than nutritional status. Br J Surg 75: 135-137, 1988.

62 - WINDSOR JA \& Hill GL. Grip strength: a measure of the proportion of protein loss in surgical patients. Br J Surg 75 880-882, 1988.

63 - KELLY RA \& MITCH WE. Creatinine, uric acid, and other nitrogenous waste products: Clinical implication of the imbalance between their production and elimination in uremia. Semin Nephrol 3: 286-290, 1983.

64 - MAULT JR et al. Oxygen consumption during hemodyalisis for acute renal failure. Trans Am Soc Artif Intern Organs 28: 510-513, 1982.

65 - SOOP M et al. Energy expenditure in postoperative multiple organ failure with acute renal failure. Clin Nephrol 31: 139-145, 1989.

66 - HASSELGREN PO et al. Current concepts of protein turnover and aminoacid transport in liver and skeletal muscle during sepsis. Arch Surg 123: 992-999, 1988.

67 - CIANCIARUSO B et al. Hepatic uptake and release of glucose, lactate and amino acids in acutely uremic dogs. Metabolism 40: p. 261-269, 1991.

68 - HORL WH \& HEIDLAND A. Enhanced proteolytic activitycause of protein catabolism in acute renal failure. Am J Clin Nutr 33: 1423-1427, 1980.
69 - ANDREWS PM \& CHUNG E. M. High dietary protein regimens provide significant protection from mercury nephrotoxicity in rats. Toxicol Appl Pharmacol 105: 288-304, 1990.

70 - CLARK AS \& MITCH WE. Muscle protein turnover and glucose uptake in acutely uremic rats. J Clin Invest 58: 39-47, 1975.

71 - DRUML W et al. Lipid metabolism in acute renal failure. Kidney Int 16: 139-142, 1983. Suppl.

72 - PIETREK J; KOKOT F \& KUSHA J. Serum 25-hydroxivitamin $D$ and parathyroid hormone in patients with acute renal failure. Kidney Int 13: 178-185, 1978.

73 - HSU CH et al. Production and metabolic clearance of calcitriol in acute renal failure. Kidney Int 33: 530-535, 1988.

74 - KOPPLE JD et al. The free and bound amino acid removed by hemodialysis. Trans Am Soc Artif Intern Organs 14: 309-313, 1973

75 - MITCH WE \& WILMORE DW. Nutritional considerations in the treatment of acute renal failure. In: BRENNER BM \& LAZARUS JM: Acute renal failure, $2^{\text {nd }}$ ed, Churchill Livingstone, New York, p. 743-765, 1988.

76 - DIAZ-BUXO JA. Clinical use of peritoneal dialysis. In: NISSENSON AR; FINE RN \& GENTILE DE. Clinical dialysis, $3^{\text {th }}$ ed, Appleton \& Lange, Norwalk, Connecticut, p. 377-425, 1995.

77 - OWE Jr WF \& LAZARUS JM. Dialytic management of acute renal failure. In: LAZARUS M \& BRENNER BM. Acute renal failure, $3^{\text {th }}$ ed, Churchill Livingstone, New York, p. 487-525, 1993.

78 - ULDALL R. Vascular access for continuous renal replacement therapy. Semin Dial 9: 93-97, 1996.

79 - ROMÃO Jr JE. Membranas biocompatíveis no tratamento dialítico da insuficiência renal aguda. J Bras Nefrol 18: 56-58, 1996.

80 - CONGER J. Does hemodialysis delay recovery from acute renal failure? Semin Dial 3: 146-148, 1990.

81 - KAPLAN AA.; PAGANINI EP \& BOSCH JP. Effect of the dialysis membrane in acute renal failure. $\mathbf{N}$ Engl $\mathbf{J}$ Med $\mathbf{3 3 2}$ 961-964, 1995.

82 - SIGLER MH \& TEEHAN BP. Continuous renal replacement therapy. In: NISSENSON AR; FINE RN \& GENTILE DE. Clinical dialysis, $3^{\text {th }}$ ed, Appleton \& Lange, Norwalk, Connecticut, p. 907-926, 1995.

83 - KJELLSTRAND CM; BERKSETH RO \& KLINKMAN $\mathrm{H}$. Treatment of acute renal failure. In: SCHRIER RW \& GOTTSCHALK CW. Diseases of the kidney , $4^{\text {th }} \mathrm{ed}$, Little Brown, Boston, p. 1501-1540, 1988.

Recebido para publicação em 04/03/98

Aprovado para publicação em 07/10/98 